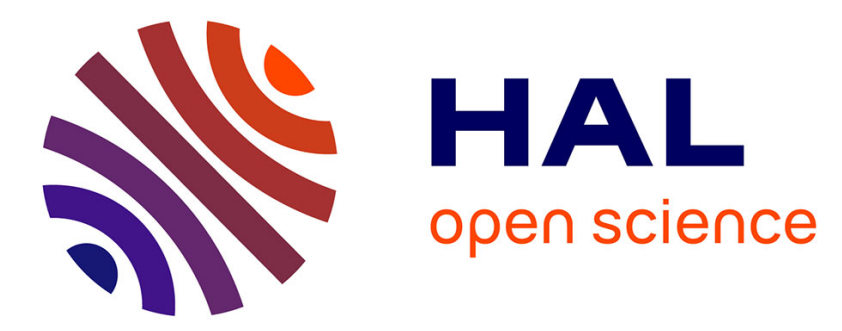

\title{
Multiple precipitation mechanisms over mountains observed by airborne Doppler radar during MAP IOP 5
}

Cheng-Ku Yu, David P. Jorgensen, Frank Roux

\section{To cite this version:}

Cheng-Ku Yu, David P. Jorgensen, Frank Roux. Multiple precipitation mechanisms over mountains observed by airborne Doppler radar during MAP IOP 5. Monthly Weather Review, 2007, 135 (3), pp.955-984. 10.1175/MWR3318.1 . hal-00203426

\section{HAL Id: hal-00203426 \\ https://hal.science/hal-00203426}

Submitted on 11 Aug 2021

HAL is a multi-disciplinary open access archive for the deposit and dissemination of scientific research documents, whether they are published or not. The documents may come from teaching and research institutions in France or abroad, or from public or private research centers.
L'archive ouverte pluridisciplinaire HAL, est destinée au dépôt et à la diffusion de documents scientifiques de niveau recherche, publiés ou non, émanant des établissements d'enseignement et de recherche français ou étrangers, des laboratoires publics ou privés. 


\title{
Multiple Precipitation Mechanisms over Mountains Observed by Airborne Doppler Radar during MAP IOP5
}

\author{
CHENG-Ku Yu \\ Department of Atmospheric Sciences, Chinese Culture University, Taipei, Taiwan \\ DAVID P. JORGENSEN \\ NOAA/National Severe Storms Laboratory, Boulder, Colorado \\ FRANK ROUX \\ Laboratoire d'Aerologie (CNRS-UPS), Toulouse, France
}

\begin{abstract}
This study uses airborne Doppler radar measurements from the Special Observing Period of the Mesoscale Alpine Programme (MAP) to document the detailed airflow and precipitation structure over the mountainous regions near the border of northeastern Italy and Slovenia as a cold frontal system moved eastward and encountered the eastern Alps on 4 October 1999, during MAP IOP5. In contrast to previously documented MAP cases, the environmental conditions associated with this case are characterized by a deep layer of strong convective instability in the lower troposphere and by a cold, northeasterly continental flow coming down from the mountains (the so-called bora wind) along the southeastern Alps. Over the study region, there are two primary mountain barriers: the Julian Alps, oriented roughly west-east with a peak mountain height of $\sim 2500 \mathrm{~m}$ and a significant variation in terrain height along its length, and the other, the Dinaric Alps, a relatively lower mountain range oriented northwest-southeast, immediately adjacent to the south of the Julian Alps. How these two mountain barriers and the northeasterly continental flow influence the precipitation, and the nature of orographic precipitation developing in a potentially unstable environment, are explicitly addressed. Comprehensive analyses of airborne Doppler radar measurements reveal significant variations of precipitation in terms of its location, intensity, and type over the mountainous region. Particularly, five distinct forcing types of precipitation are evident for this case: slope convergence triggering, upslope triggering, weak slope convergence triggering, gap exit convergence triggering, and slope convergence forced stratiform. These precipitation characteristics are found to be closely related to the environmental thermodynamics, orographic features, and the complicated interactions between the southerly/southwesterly flow, northerly continental flow, and the orography. Details of these important observational aspects are elaborated upon in this paper.
\end{abstract}

\section{Introduction}

One of the most important challenges of predicting rainfall over regions adjacent to mountain ranges is properly assessing the significance of the orography to the precipitation distribution and intensity (Smith 1979; Banta et al. 1990). As discussed in Houze (1993), sev-

Corresponding author address: Dr. Cheng-Ku Yu, Department of Atmospheric Sciences, Chinese Culture University, 55, HwaKang Road, Yang-Ming-Shan, Taipei 111, Taiwan.

E-mail: yuku@faculty.pccu.edu.tw eral fundamental mechanisms of orographic precipitation such as the seeder-feeder mechanism, upslope condensation, and the upslope, upstream, thermal, and leeside triggering of convection have been proposed to explain observations of some of the precipitation events occurring in the presence of orography. Conceptually, these previously recognized precipitation mechanisms represent an idealized prototype for various types of orographic precipitation that might occur in the real troposphere. Nevertheless, in recent years, increasing evidence in both the observational and modeling perspective (e.g., Houze and Medina 2005; Galewsky and 
Sobel 2005 and many others) have strongly suggested that precipitation processes in the vicinity of mountains are often beyond the unified theoretical framework and usually more complicated, because of the varied synoptic environment, the inherent complexity of orographic geometries, the influences of convectively generated circulations, and the dynamical interactions among these aforementioned factors. This study represents a continuous effort to improve our general understanding of orographic precipitation with the detailed analysis of airborne Doppler radar measurements. Particularly the physical relationship of the precipitation structure and intensity will be examined with the ambient conditions and orographic features.

Understanding of orographic precipitation has been largely limited by the lack of detailed flow and precipitation information over and near topography. In view of this, several important field experiments were conducted recently over different geographical locations, such as the Coastal Observation and Simulation with Topography (COAST; Bond et al. 1997), the California Landfalling Jets Experiment (CALJET; Ralph et al. 1999), the Mesoscale Alpine Programme (MAP; Bougeault et al. 2001), the Intermountain Precipitation Experiment (IPEX; Schultz et al. 2002), and the Second Improvement of Microphysical Parameterization through Observational Verification Experiment (IMPROVE-II; Stoelinga et al. 2003). These field experiments, particularly with deployment of groundbased and airborne Doppler radar platforms, have attempted to document the detailed flow and precipitation structures in regions over and adjacent to complex terrain and to understand their underlying dynamics. With the analysis of Doppler radar observations collected from these field experiments, a significant number of recent observational studies has revealed important aspects of how the orographically influenced circulations modulate the precipitation under a variety of synoptic conditions (e.g., Yu and Smull 2000; Medina and Houze 2003; Georgis et al. 2003; Neiman et al. 2004; Cox et al. 2005; Medina et al. 2005; Pradier et al. 2005; Woods et al. 2005). Some additional aspects were revealed from modeling studies of the orographic precipitation events occurring during these experiments by utilizing a high-resolution numerical simulation (e.g., Colle and Mass 1996; Asencio et al. 2003; Richard et al. 2003; Chiao et al. 2004; Lin et al. 2005; Garvert et al. 2005). These studies have shown the crucial role of orographic blocking, convective instability, the forced lifting over the windward slopes, and the microphysical processes in the intensification and modulation of the observed precipitation. Because nearly all of these field experiments focused on the investigation of wintertime storms as they interacted with a mountain barrier, they have substantially advanced our understanding of precipitation processes, particularly for a stably stratified moist flow over orography.

Convective clouds formed by the release of ambient unstable air are likely to intensify precipitation over mountains through the seeder-feeder process (e.g., Browning et al. 1974; Parsons and Hobbs 1983), or produce pronounced precipitation upstream of mountains through orographic blocking (Grossman and Durran 1984), or generate cold-air outflow, which interacts with ambient flow to maintain the moist deep convection embedded within the mountainous precipitation systems (Jou 1994; Chen et al. 1999). This type of mechanism is important not only for its potential enhancement of precipitation, but also for its ability to significantly increase precipitation efficiencies and rainfall accumulations over mountains and adjacent terrain (Smith 1982; Kirshbaum and Durran 2004). In certain appropriate circumstances, it may contribute substantially to the occurrence of flash floods. A typical and well-known example is the Big Thompson storm, occurring adjacent to the Rocky Mountains. Caracena et al. (1979) used surface and upper-air observations and radar data to investigate this event and found that the orographic uplift of the low-level inflow air played an important role in the release of environmental convective instability and that the light winds at steering levels allowed the storm to remain quasi-stationary over the foothills. Nevertheless, owing to the lack of information on the three-dimensional wind structure and evolution, these previous studies have provided only a gross aspect of orographic precipitation developing in a potentially unstable environment.

The primary objective of this study is to use airborne Doppler radar measurements from the Special Observing Period of MAP to investigate the detailed airflow and precipitation structure over the mountainous regions near the border of northeastern Italy and Slovenia as a cold frontal system moved eastward and encountered the eastern Alps on 4 October 1999, during MAP IOP5. The National Oceanic and Atmospheric Administration (NOAA) P-3 and the National Center for Atmospheric Research (NCAR) Electra aircraft conducted a very successful coordinated mission during this IOP (Bougeault et al. 2001) and provided a comprehensive dataset of Doppler radar observations over the mountainous region during and after the passage of the front. There are two distinct scientific aspects for this particular event.

First, the upstream environment was characterized by a deep layer of strong convective instability in the lower troposphere. This precipitation episode provides 
a valuable opportunity to explore our knowledge of orographic precipitation occurring in a potentially unstable environment. Another MAP event (MAP IOP2b) is also characterized by potentially unstable rain and has been studied by several researchers (Asencio et al. 2003; Georgis et al. 2003; Medina and Houze 2003; Chiao et al. 2004), but unlike IOP5, precipitation during the IOP2b event occurred primarily over the southern slopes of the western Alps in northern Italy (i.e., the main target area of the experiment) with a very different airflow orientation with respect to the orographic barrier. Moreover, its associated convective instability was much weaker than that of the IOP5 event.

Second, major precipitation for the IOP5 case developed over the Friuli region (i.e., the southern slopes of the eastern Alps in northeastern Italy), one of the three Alpine regions with the climatological maximum of heavy rainfall events (Frei and Schär 1998). Climatologically, this geographical region also experiences the strongest and most frequent so-called bora wind (Smith 1987; Kljun et al. 2001), a cold northeasterly flow coming down from the mountains along the southeastern Alps. Few past Alpine studies have suggested a close relationship between the occurrence of bora winds and the Friuli precipitation events (Buzzi and Foschini 2000; Lazić and Tošić 1998), although there are still significant gaps in our knowledge of such bora-induced precipitation due to the lack of detailed observations in this geographical region. The synoptic condition associated with the present case, in addition to the presence of a propagating frontal system, was also accompanied by a cold northeasterly flow originating from the north of the eastern Alps. With the advantage of specially extensive airborne Doppler observations collected during this event, processes relevant to how this boralike airflow influences the mountainous precipitation can be uniquely explored in this study.

It should be noted that some preliminary synoptic and mesoscale aspects of the MAP IOP5 have been described in a recent paper by Pradier et al. (2002, hereafter referred to as PCR). Using a limited observation of the NCAR Electra airborne Doppler radar and the examination of corresponding numerical simulations, PCR have suggested that the low-level convergence between the cold northerly flow from the north of the Alps and the southerly flow is an important contributor to the development of frontal precipitation. Nevertheless, specific processes regarding the modification of the precipitation by the cold northerly flow and the orography were not explicitly addressed in PCR. Furthermore, PCR did not give details of the complicated mesoscale precipitation features observed over the mountainous region during the IOP5 event. Hence, the main focus of the present study is to perform more complete and comprehensive analyses of airborne Doppler observations as well as other conventional measurements available during this IOP. In this paper, we will show how these factors, such as the presence of synoptic frontal flow and the cold northerly flow and the influences of topography, interact with each other to determine the type, location, and intensity of orographic precipitation for the present case.

\section{Data processing and analysis methods}

Intensive observations by the NCAR Electra and NOAA P-3 aircraft for this case were primarily conducted over the mountainous region near the border of Italy and Slovenia between 0700 and 1130 UTC 4 October 1999. The geographic region for the Electra and P-3 flight tracks and the topographic features over the eastern Alps are shown in Fig. 1. Airborne Doppler radar data, during MAP IOP5, were gathered primarily over the mountainous regions. Hence, the raw radar data contain considerable nonmeteorological radar echoes, primarily mountain clutter and second-trip echo, exclusively related to the local topographic features. Figure 2 is an example of an individual $360^{\circ}$ sweep of the X-band tail-mounted Doppler radar illustrating these different types of contamination. Similar to the concept of the automatic editing proposed by Bousquet and Smull (2003), an alternative methodology was applied in this study to remove these nonmeteorological radar echoes automatically. For the ground and mountain clutter removal, the altitudes of each range gate are calculated and then compared to a highresolution (30" latitude, equivalent to about $925 \mathrm{~m}$ ) digital topographic dataset. Once the difference of altitude between a range gate along the radar beam and the terrain surface is found to be smaller than a specified tolerance, ${ }^{1}$ the gate is assumed to be the first location of the radar beam intersecting the ground and thus remaining gates beyond it are all considered to be clutter and are removed. The above criteria can be expressed mathematically as

$$
Z_{g}-Z_{h} \leq H \times\left(1-\frac{\text { Elev }}{180}\right),
$$

in which $Z_{g}$ is the altitude of the radar gate, $Z_{h}$ is the terrain height, $H$ is an arbitrary value of height (an empirical value of best removal is found to be $\sim 500 \mathrm{~m}$ for this case), and Elev is the elevation angle of radar

\footnotetext{
${ }^{1}$ This is due to the uncertainties associated with the finite size of the antenna lobe and gate width.
} 

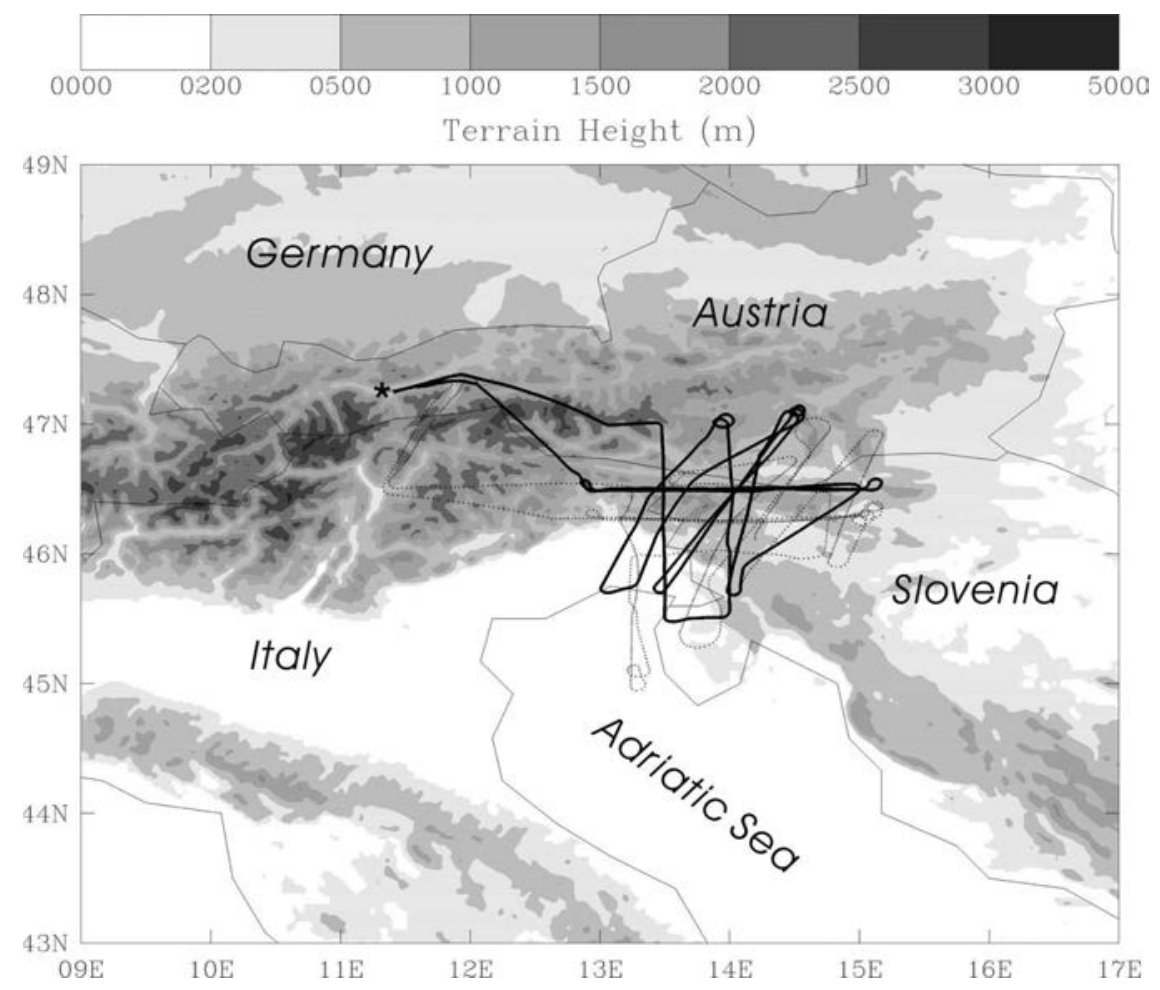

FIG. 1. Topographic features over the eastern Alps and flight track (dotted line for P-3 aircraft and thick line for Electra aircraft) on 4 Oct 1999 during MAP IOP5. The asterisk indicates the flight base of the aircraft at Innsbruck.

beam from the zenith, ranging from $\sim 20^{\circ}$ to $\sim 160^{\circ}$. Note that the critical values for the difference of altitude between the gate and the terrain surface [i.e., the right-hand side of (1)] increase with decreasing elevation angle, which can effectively reduce the inclusion of ground and/or mountain echoes for those more horizontal radar beams, particularly at longer-range distance away from the radar. A technique of deducing these navigation errors proposed by Georgis et al. (2000) was also applied to complement the automated procedure, which allows for a better determination of each gate location relative to the topography.

The appearance of the second-trip echo is pretty common for MAP airborne Doppler radar data. The basic character of this contamination is closely related to the orographic features over regions beyond the maximum range of Doppler radar. The second-trip echoes are typically found in radar beams having small elevation angles (from the horizontal) on both sides of the aircraft and are characterized by a prominent alongbeam discontinuity in radial velocity and a relatively weak reflectivity (Fig. 2). In principle, the gradient of radial velocities in the along-beam direction can be useful for identifying the second-trip echo. Hence, in the automated procedure, the radar data is considered to be second-trip echo when the calculated along-beam velocity gradient, in which the angles of radar beams are within $\pm 20^{\circ}$ from the horizontal, exceeds an empirical value $\left(0.04 \mathrm{~s}^{-1}\right.$ chosen for this case). However, it should be noted that, as shown in Fig. 2b, the secondtrip echoes are also characterized by a pronounced variation of the along-beam gradient of radial velocities, particularly with few gates having a relatively small velocity gradient adjacent to or embedded within those having a pronounced velocity gradient. It can be speculated that a significant amount of second-trip echoes still cannot be removed successfully if the above criteria is processed on the basis of gate-to-gate calculation only. An alternative way to mitigate this problem is to identify the second-trip echoes performed for an arbitrary interval of consecutive gates. This interval of gates would be considered as second-trip echo entirely as long as any of those gates within the interval meet the criteria. For this particular IOP event, the best interval for the removal of the second-trip echo is five gates. Additionally, other contamination, such as gates having unreasonable values of radar velocity and along-beam discontinuities, are also precluded in this automated procedure.

To evaluate the capability of this procedure, indi- 


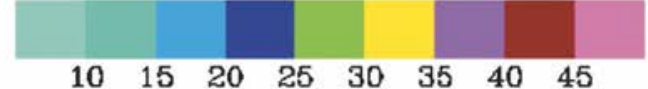

$\begin{array}{llllllll}10 & 15 & 20 & 25 & 30 & 35 & 40 & 45\end{array}$
MAP IOP5 TIME $=\emptyset 72758$

head $=184.7 \quad \mathrm{~N}=154$

Fore Scan
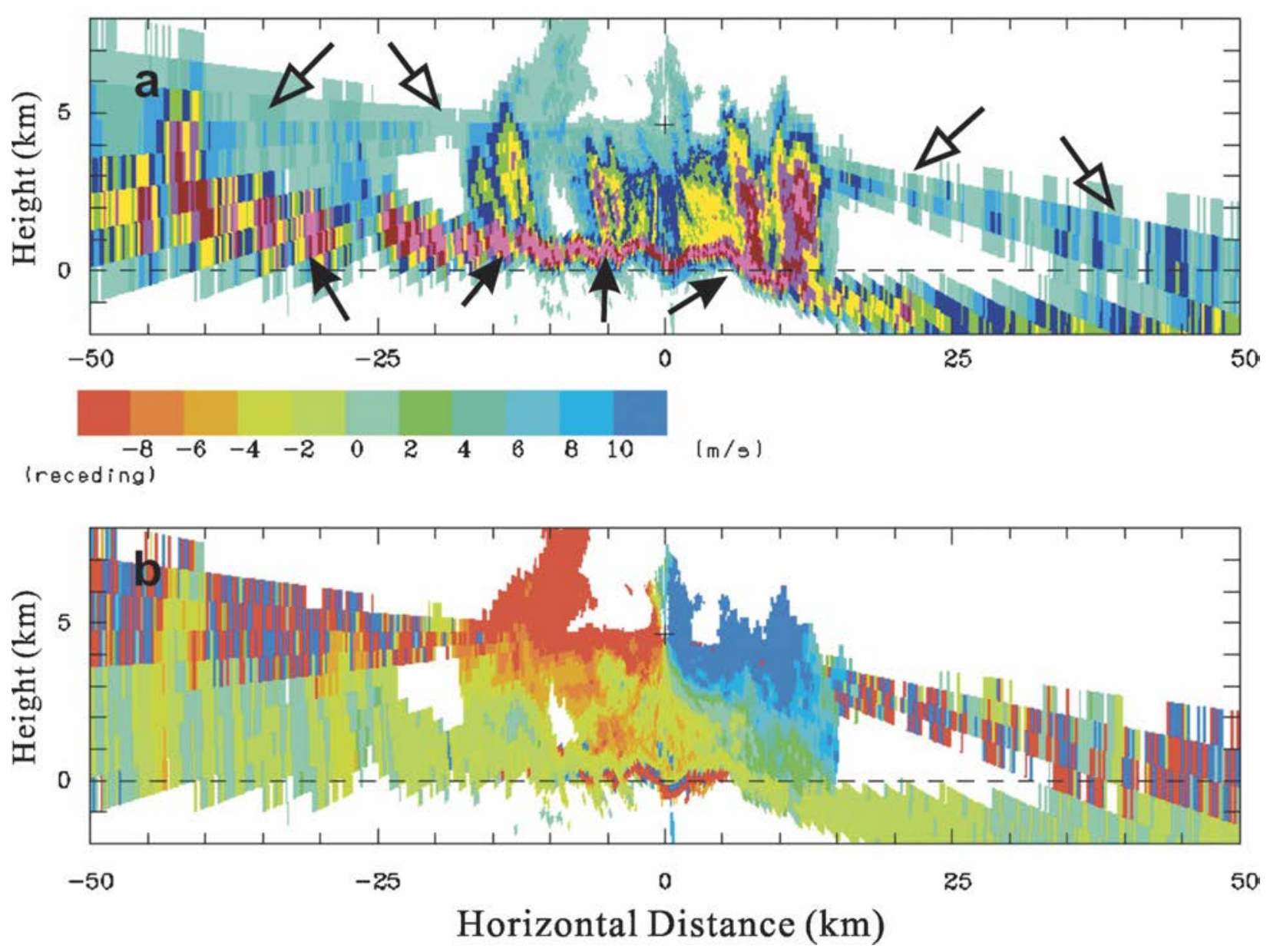

FIG. 2. Vertical cross sections of (a) radar reflectivity ( $\mathrm{dBZ}$ ) and (b) radial velocity $\left(\mathrm{m} \mathrm{s}^{-1}\right)$, constructed from individual fore scan of the X-band tail-mounted Doppler radar aboard the Electra aircraft at 0727 UTC 4 Oct 1999 during MAP IOP5. The aircraft's position is indicated by the plus sign, flying into the plane of the section at an altitude near $4668 \mathrm{~m} \mathrm{MSL}$. In (a), ground-mountain clutter and the second-trip echo are highlighted by solid and hollow arrows, respectively.

vidual $360^{\circ}$ sweeps of the X-band Doppler radar were examined with the procedure applied. Example plots of the vertical cross section from a fore scanning of the NCAR Electra airborne Doppler radar before and after applying the automated editing procedure are shown in Fig. 3. There was considerable mountain clutter near the ground surface and second-trip echoes on both sides of the aircraft as seen in the plot of raw radar sweep data (Fig. 3a). When applying the editing procedure without the Inertial Navigation System (INS) error correction, some mountain clutter still could be found to the left of and below the aircraft (Fig. 3b). The
INS errors retrieved from the flight leg 0720-0725 UTC encompassing the sweep data were then taken into account to recalculate the location of each gate. For this leg, the derived correction values for roll, pitch, heading, range delay, and radar location $(x, y, z)$ were equal to $-1.9^{\circ},-1.2^{\circ},-0.01^{\circ}, 292,-1286,-886$, and $5 \mathrm{~m}$, respectively. When these INS corrections were incorporated into the procedure and the second-trip echo removal scheme was also applied, nearly all clutter was successfully removed, as shown in Fig. 3c.

In this study, three-dimensional airflow and precipitation over the study region are obtained by a pseudo- 

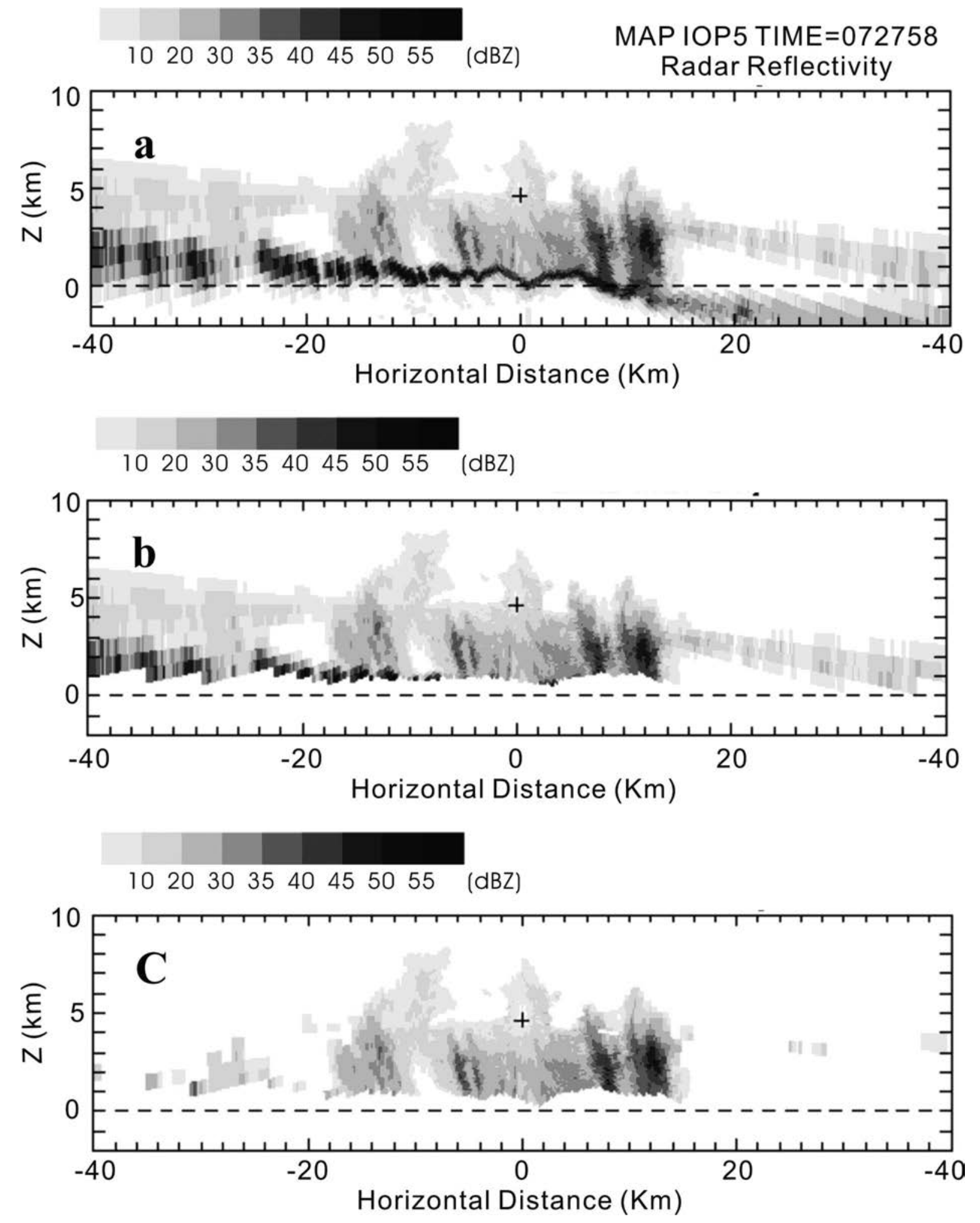

FIG. 3. Vertical cross sections of radar reflectivity (dBZ) constructed from the $360^{\circ}$ sweep of the X-band Doppler radar aboard the NCAR Electra 0727 UTC 4 Oct 1999 during MAP IOP5. (a) Raw data without applying any editing procedure. (b) Product after removing those gates below mountain heights but without taking the INS errors into account. (c) Final product after applying the automated editing procedure developed in this study. The aircraft position is indicated by the plus sign at an altitude near $4668 \mathrm{~m}$ (MSL). 
dual-Doppler synthesis derived from multiple-view radial velocity and reflectivity data as described by Jorgensen et al. (1994). The horizontal and vertical analysis grid spacing were set to 1.5 and $0.25 \mathrm{~km}$, respectively, over a volume encompassing $120 \times 120 \mathrm{~km}^{2}$ in the horizontal and $12 \mathrm{~km}$ in the vertical, with the lowest analysis level located at $0.25 \mathrm{~km}$ above mean sea level (MSL). The locations of four dual-Doppler analysis domains (with letters D1, D2, D3, and D4, respectively) analyzed in this study are shown by the inset boxes in Fig. 4. Vertical air motions were obtained through an iterative procedure by assuming anelastic continuity through downward integration from an upper-boundary condition of zero vertical motion at echo top. Because the integration proceeds from low to high air densities, vertical velocity errors that accumulate during the integration are damped rather than amplified (Matejka and Bartels 1998). In this computation, we assume that the contribution of the topography to the vertical velocities over the terrain surface is relatively small compared to that associated with convective clouds and is thus ignored. Given the difficulty of retrieving reliable surface winds from airborne Doppler radar data and inherently small values of topographically forced vertical motions (generally a few tens of centimeters per second over the study region), this assumption should be still applicable and would probably not cause significant bias in the synthesized winds.

\section{Environmental overview}

Synoptic conditions accompanying MAP IOP5 have been described in PCR; thus, we will only emphasize those environmental aspects that are directly relevant to the Doppler-observed airflow and precipitation structures. This IOP event started with some scattered precipitation developing over the southern slopes of the eastern Alps around 0500 UTC 4 October 1999, as a surface cold front with a deep midlevel trough located over the western Alps approached the study region. To the east of the trough, the low-level large-scale flow was generally from the south, with warmer and moister air from the Adriatic Sea impinging the southern slopes of the eastern Alps (Fig. 5). An obvious cyclonic turning of the wind from westerlies/southwesterlies to southsouthwesterlies characterized the low-level frontal zone over northeast Italy. In addition, cold northeasterly flow with low $\theta_{\mathrm{e}}$ air was also observed immediately south of the eastern end of the Alps and appeared to encounter southwesterlies to form a large-scale confluent zone oriented approximately west-east. As suggested by PCR, this cold northerly flow (hereafter referred to as the continental flow) progressed southward slowly with time. It originated apparently from north of the Alps, where the deflected westerlies warped around the eastern Alps (Fig. 5). In section 4, we will elaborate how these two distinct flow patterns (i.e., the northerly continental flow and southerly flow) and their associated convergence relate to the observed mountainous precipitation, in terms of its structure and location relative to the terrain features.

During the aircraft observation, the surface cold front oriented approximately south-north moved eastward at a mean speed of $\sim 10 \mathrm{~m} \mathrm{~s}^{-1}$ across the study region (Fig. 4). A sequence of reflectivity fields observed from the Fossalon operational radar (location in Fig. 4) reveals some important aspects of precipitation over the study region during and after the passage of the surface cold front. During the early-to-middle portion of the flight (before $\sim 0900$ UTC), when the northern segment of the surface front was located in the vicinity of the Julian Alps, precipitation patterns were mainly characterized by a narrow zone of intense reflectivities (maximum values $>50 \mathrm{dBZ}$ ) extending from the southern slopes of the Julian Alps to a location far south and over the Gulf of Venezia (Fig. 6a). This narrow precipitation band coincident with the low-level frontal wind shift zone seen in dual-Doppler observations marked the position of the surface cold front. During this period, the precipitation nearby the northern part of the front exhibited features distinct from its southern part over the Gulf of Venezia where only a clear-cut narrow rainband was present. Particularly, considerable radar echoes were found in regions near and ahead of the surface cold front. The precipitation observed in the prefrontal zone appeared to be less organized but was evident over different time periods. As will be shown later by airborne Doppler observations, their causes were actually attributed to different orographic processes.

While the surface cold front moved away from the region of interest during the latter part of the flight (after $\sim 0900$ UTC, Fig. 4), considerable precipitation was still associated with the surface front located over the Dinaric Alps (Fig. 6b). Nevertheless, the frontal precipitation had become wider and much less intense and organized, presumably due to the influence of orography. In contrast to a generally convective nature observed earlier (Fig. 6a), precipitation over the southern slopes of the Julian Alps and the northern portion of the Dinaric Alps had a relatively uniform pattern of radar reflectivities (Fig. 6b), suggesting the presence of stratiform rain during this period. This postfrontal precipitation lasted $\sim 2.5 \mathrm{~h}$ over the mountainous region until the end of the flight mission. Both the NCAR Electra and the NOAA P-3 research aircraft executed several east-west-oriented Doppler legs passing 


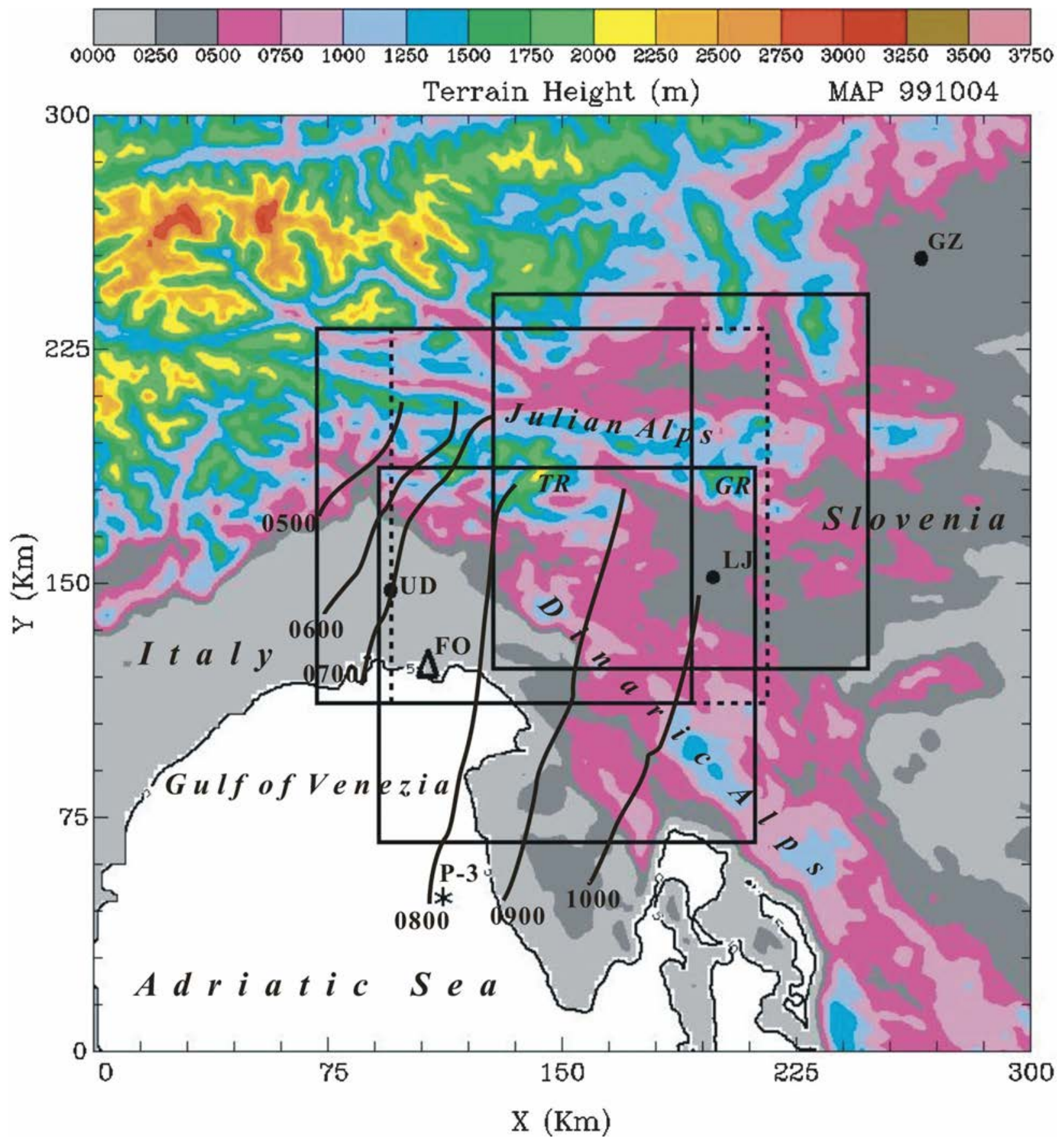

FIG. 4. Detailed view of topography in the vicinity of the Julian and Dinaric Alps. Terrain height (m MSL) is indicated by color shading at the 250-m interval. Inset boxes locate dual-Doppler analysis domains: the left, low, and right boxes represent domain D1, D2, and D3, respectively, and the middle dashed box represents domain D4. Isochrones of NCFR (thick solid line) observed by the Fossalon radar (FO, location indicated by hollow triangle) with a 1-h interval depicting locations of the surface cold front from 0500 to 1000 UTC 4 Oct 1999. Locations of three sounding stations [Udine (UD), Graz (GZ), and Ljubljana (LJ)] and the P-3 dropsonde are indicated by dots and asterisk, respectively. Locations of local mountain peaks [Mt. Triglav (TR) and Grintovec (GR)] along the Julian Alps are also indicated. 


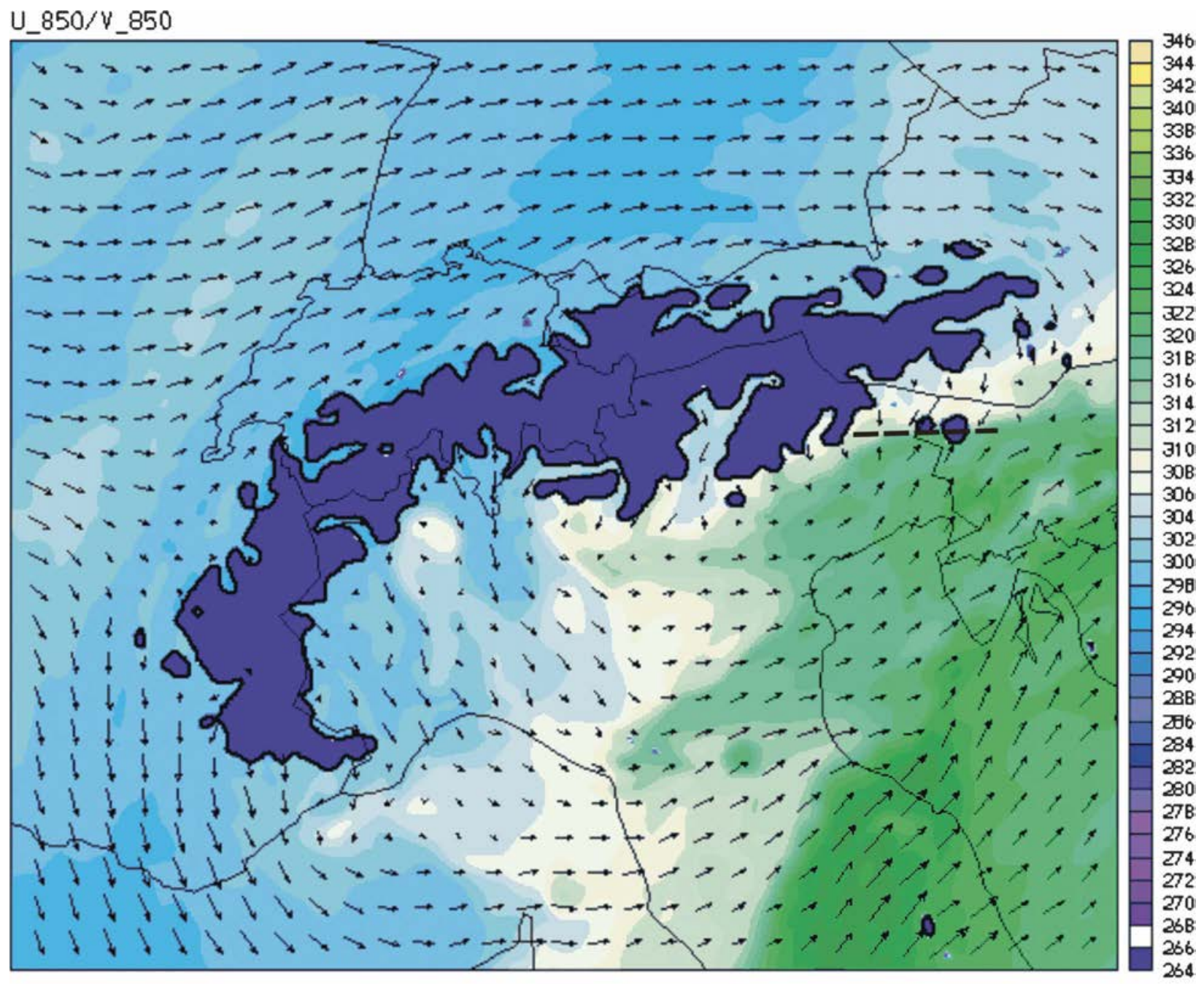

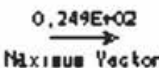

FIG. 5. The atmospheric Mesoscale Compressible Community numerical forecast model (MC2) 850-hPa wind field and equivalent potential temperature (K, color shading, key at right) around the Alps valid at 0600 UTC 4 Oct 1999. Heavy dashed line marks the boundary between the cold northeasterly continental flow and the warm southerly flow. The purple shading represents the Alps above a height threshold of $\sim 1500 \mathrm{~m}$ (MSL) (adapted from the MAP Data Centre).

through the precipitation region (Figs. 1 and 6b), which allows documentation of the detailed airflow and precipitation structures over mountains and identification of the possible processes resulting in its occurrence.

Thermodynamical profiles located $\sim 30 \mathrm{~km}$ upstream of the Julian Alps from a sounding released from Udine (location indicated in Fig. 4) at 0000 UTC 4 October (Fig. 7a) reveal nearly saturated conditions in the prefrontal flow throughout the low to midtroposphere with relatively dry air above $\sim 5.5 \mathrm{~km}$. Low-level winds veered with height from southerly/south-southeasterly in the lowest $1 \mathrm{~km}$ to southwesterly at around $1.5 \mathrm{~km}$ and above. A deep layer of convective instability was present from the surface to a height of $\sim 2.5 \mathrm{~km}$, with stable-to-neutral convective stability aloft (Fig. 8). The value of convective available potential energy (CAPE) was about $1500 \mathrm{~J} \mathrm{~kg}^{-1}$ (PCR). As indicated by a P-3 dropsonde taken $\sim 40 \mathrm{~km}$ ahead of the surface front at $\sim 0710$ UTC (Figs. $7 \mathrm{~b}$ and 8 ), the thermodynamic characteristics far upstream of the mountains over the Gulf of Venezia were generally similar to those of the Udine sounding, except for a slightly stronger convective instability with a $\theta_{\mathrm{e}}$ difference of about $20 \mathrm{~K}$ between the surface and $2.5-\mathrm{km}$ altitude over the sea, compared to a difference of about $15 \mathrm{~K}$ over Udine. The surface cold front passed the Udine station at $\sim 0700$ UTC (Fig. 4) 

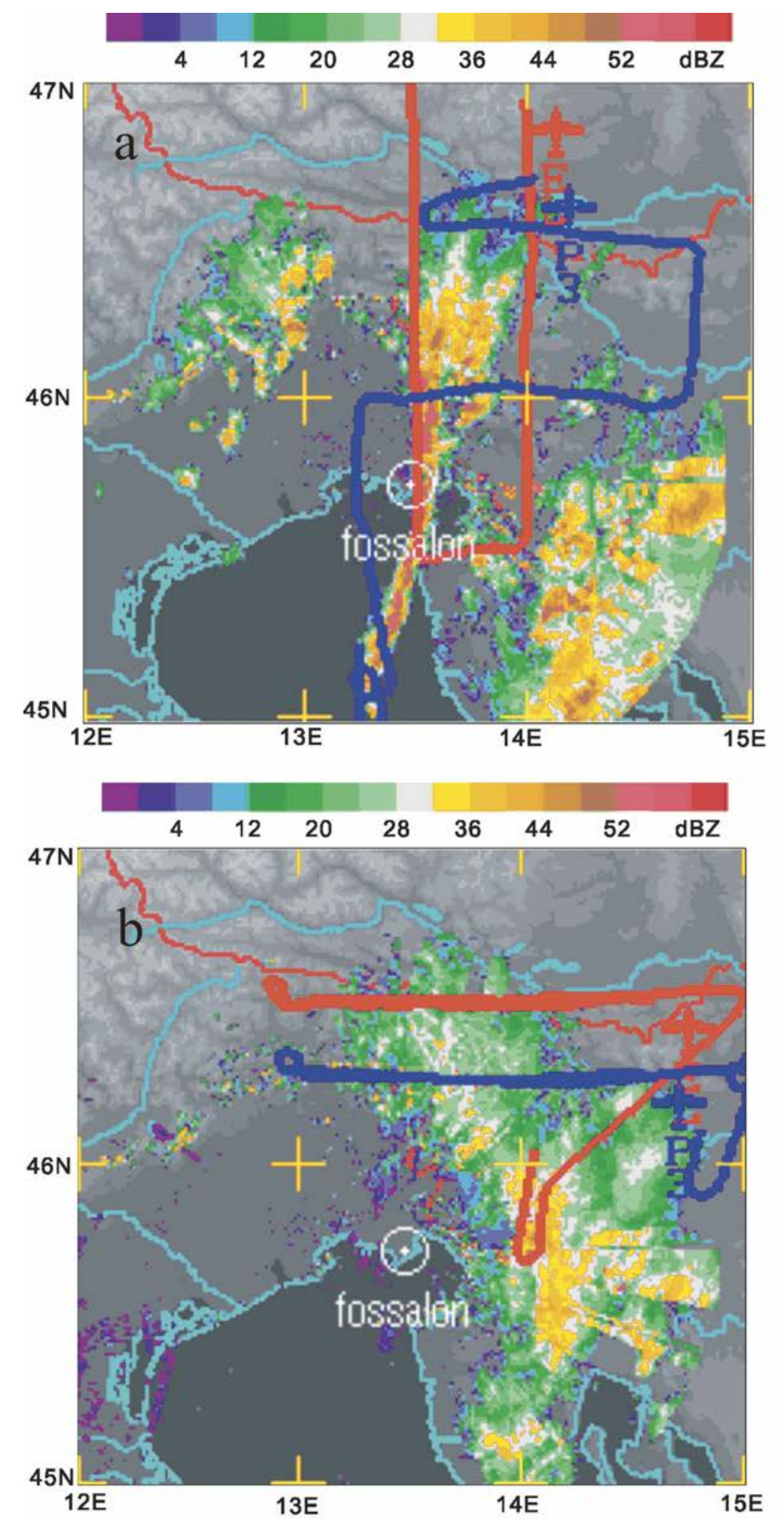

FIG. 6. Horizontal structure of radar reflectivity (dBZ) from the Fossalon radar at (a) 0800 UTC 4 Oct 1999 and (b) 1100 UTC 4 Oct 1999. In (a) and (b), flight patterns (red line for Electra aircraft and blue line for P-3 aircraft) during the interval encompassing the analysis time are also indicated. 

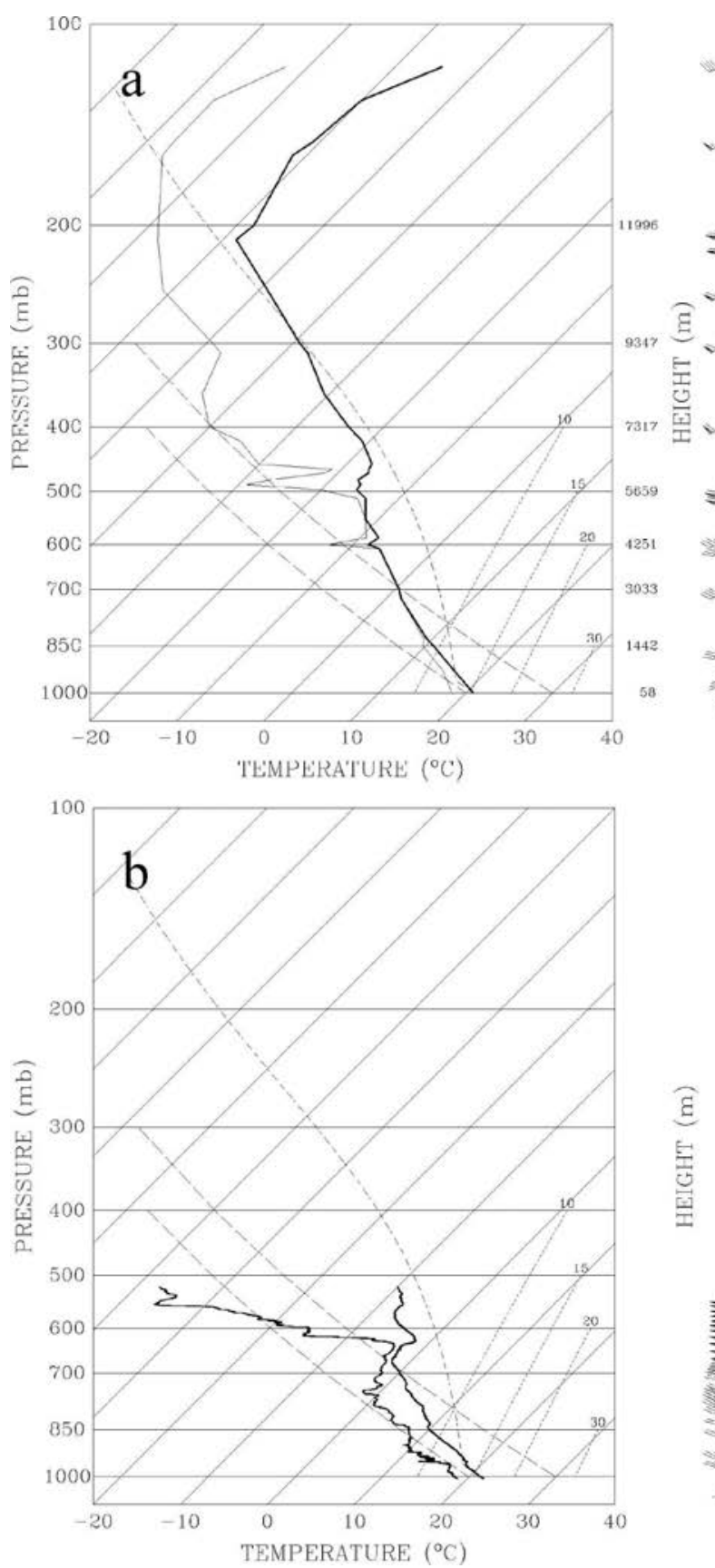

FIG. 7. Skew $T-\log p$ plot. (a) The Udine sounding taken at 0000 UTC 4 Oct 1999 and (b) the P-3 dropsonde (location indicated in Fig. 4) released at $\sim 0710$ UTC 4 Oct 1999 . Full wind barbs correspond to $5 \mathrm{~m} \mathrm{~s}^{-1}$, half barbs to $2.5 \mathrm{~m} \mathrm{~s}^{-1}$.

and hence the Udine sounding taken at 1200 UTC should provide some thermodynamic information representative of the postfrontal environment. However, during the morning of 4 October, the southward progression of the northerly continental flow had already passed over the Udine station and had replaced the

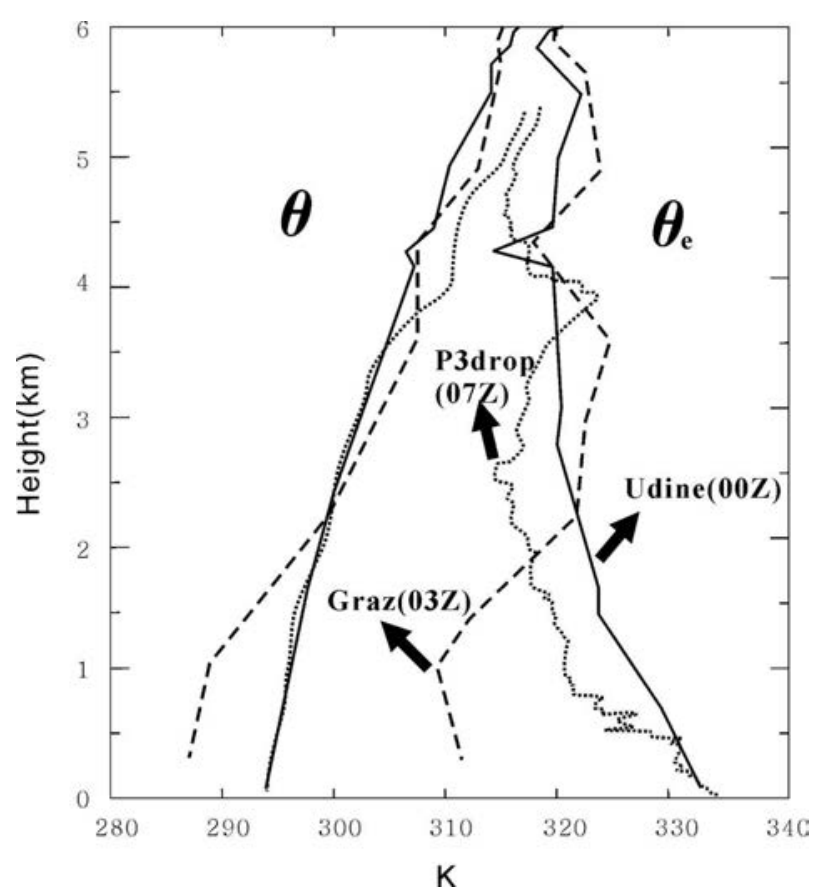

FIG. 8. Vertical profiles of potential temperature and equivalent potential temperature observed from the Udine sounding at 0000 UTC 4 Oct 1999 (solid line), the P-3 dropsonde at 0710 UTC 4 Oct 1999 (dotted line), and the Graz sounding at 0300 UTC 4 Oct 1999 (dashed line).

postfrontal southwesterly flow within the boundary layer (below $\sim 1.5 \mathrm{~km}$; see Fig. $4 \mathrm{~b}$ in PCR). An alternative thermodynamic profile of the postfrontal troposphere (not shown) is obtained by incorporating the surface temperature measured at Udine just before the arrival of the continental flow to the 1200 UTC Udine sounding. It indicates characteristics generally similar to those of the prefrontal sounding seen in Fig. 7a but with a temperature drop of $\sim 1^{\circ}-2^{\circ} \mathrm{C}$ (compared to the prefrontal southerly/southwesterly flow) in the mid- to low troposphere. Moreover, the prevailing southwesterlies were found to be drier and stronger (maximum wind speed of $\sim 45 \mathrm{~m} \mathrm{~s}^{-1}$ ) in the mid- to high troposphere.

For the case studied here, the local topography in the region of aircraft observation exhibits two primary directions, in which the Julian Alps and Dinaric Alps are oriented $\sim 10^{\circ}$ and $\sim 43^{\circ}$ clockwise from the east-west (Fig. 4). The low-level southerly oncoming flow, estimated from the 0000 UTC Udine sounding and P-3 dropsonde, brought cross-barrier winds of $10-14 \mathrm{~m} \mathrm{~s}^{-1}$ (averaged below the mean mountain height: $2 \mathrm{~km}$ for the Julian Alps and $1.25 \mathrm{~km}$ for the Dinaric Alps) approaching the southern slopes of the Julian and Dinaric Alps. The Brunt-Väisälä frequency averaged below 2 and $1.25 \mathrm{~km}$ is equal to $8.8 \times 10^{-3} \mathrm{~s}^{-1}$ and $9.1 \times 10^{-3} \mathrm{~s}^{-1}$, 
respectively. With these values, we obtain a Froude number $\left(F_{r}=U / N h\right.$; where $U$ is the upstream wind speed, $N$ is the Brunt-Väisälä frequency, and $h$ is the mountain height) in the prefrontal environment approximately equal to 0.8 for the Julian Alps and 0.9 for the Dinaric Alps. These values are somewhat larger than the critical Froude number of upstream blocking ( 0.67) suggested by Chen and Lin (2005) for a conditionally unstable flow over idealized Alpine mountains. In these conditions, the development of convective clouds was possible over the two orographic barriers.

The basic thermodynamic characteristics over the eastern Alps, where the lower troposphere was occupied by the northerly continental flow (Fig. 5), were obtained using a Graz sounding (at 0300 UTC 4 October) located $\sim 70 \mathrm{~km}$ northeast of the Julian Alps (Fig. 4). As shown in Fig. 9, the temperature for the northerly flow was significantly colder than that of the southerly flow south of the Julian Alps, with a maximum temperature difference of about $9^{\circ} \mathrm{C}$ near the ground surface ( $\sim 350 \mathrm{~m}$ above mean sea level). This low-level northerly flow was also characterized by a stronger stratification than the southerly flow, particularly with an enhanced static stability marking the transition zone (between 1 and $2 \mathrm{~km}$ ) from the northerly underneath to the southerly aloft (Figs. 8 and 9). Wind profiles from the Graz sounding suggest that the vertical extent of the cold northerly continental flow was somewhat shallow up to only $\sim 1.5 \mathrm{~km}$. However, its depth, as deduced from airborne Doppler radar observations (to be shown), appeared to be much deeper over the northern slopes of the Julian Alps. Above the top of the northerly flow $(>\sim 1.5 \mathrm{~km})$, both the temperature and stratification were similar on the southern and northern sides of the Julian Alps where strong southwesterlies prevailed. In contrast to the prefrontal southerly flow, no obvious convective instability associated with the northerly flow could be found.

\section{Airflow and precipitation in the vicinity of mountains}

\section{a. Dual-Doppler analysis during the early to midportion of the flight}

\section{1) BAsic Structure of THE 0720-0735 UTC ANALYSIS}

As described in section 3 , during the early to midportion of the flight, the precipitation patterns in the vicinity of the Julian Alps were much more complicated than those far upstream of the mountains over the Gulf of Venezia. A sequence of airborne Doppler observations made near the surface cold front during this pe-

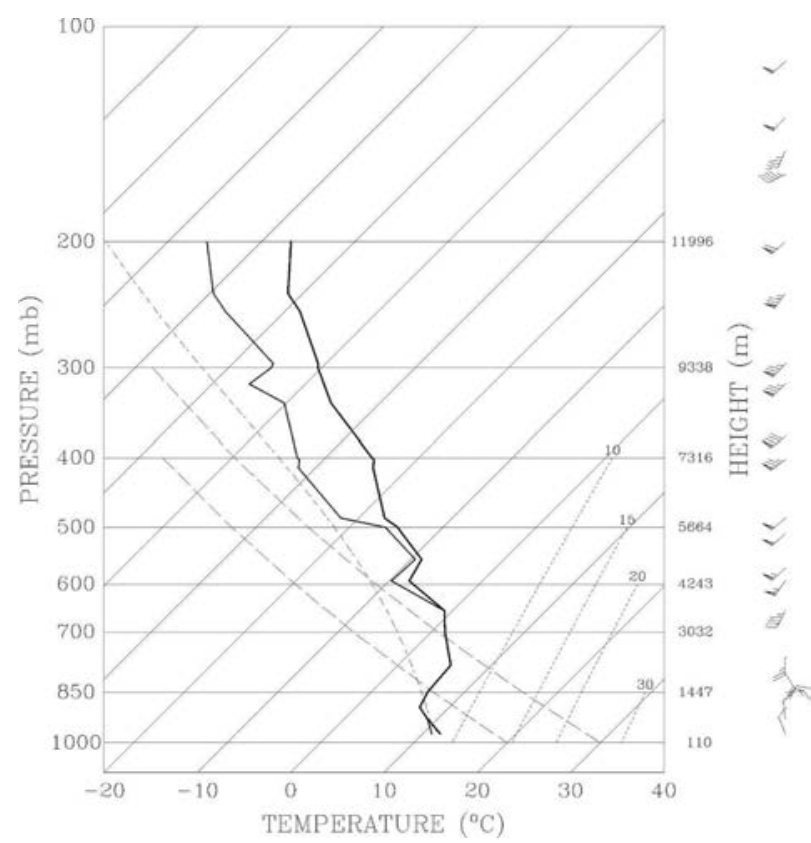

FIG. 9. Same as in Fig. 7 but showing the Graz sounding (location indicated in Fig. 4) taken at 0300 UTC 4 Oct 1999.

riod further reveals detailed aspects of the mountainous precipitation. Dual-Doppler synthesis results for this analysis correspond to the domain D1 (cf. Fig. 4) and are first selected to show the airflow and precipitation structures over and immediately upstream of the southern slopes of the Julian Alps. The 4.25-km radar reflectivity and horizontal winds are shown in Fig. 10. This level is high enough to preclude any data gaps due to the presence of the mountains so that it can demonstrate well the primary mesoscale precipitation patterns over mountains. Consistent with the large-scale precipitation pattern shown in Fig. 6a, an obvious precipitation mode of linear organization was evident and oriented approximately south-north at a location roughly along $X=36 \mathrm{~km}$. This precipitation band, except near its northern end, was located over the flat terrain region. It was characterized by a narrow but intense radar reflectivity and was also coincident with the low-level frontal wind shift zone from the postfrontal westerly/southwesterly flow to the prefrontal southerly/southsouthwesterly flow seen at lower analysis levels (not shown). This band was thus interpreted to be a narrow cold frontal rainband (NCFR; Hobbs and Persson 1982). As evident in Fig. 10, the NCFR was marked by multiple centers of very heavy precipitation (maximum radar reflectivities $>45 \mathrm{dBZ}$ ), with relatively less intense precipitation between these maximum precipitation cores. These discrete cores of heavy precipitation and intervening regions of lighter precipitation along 


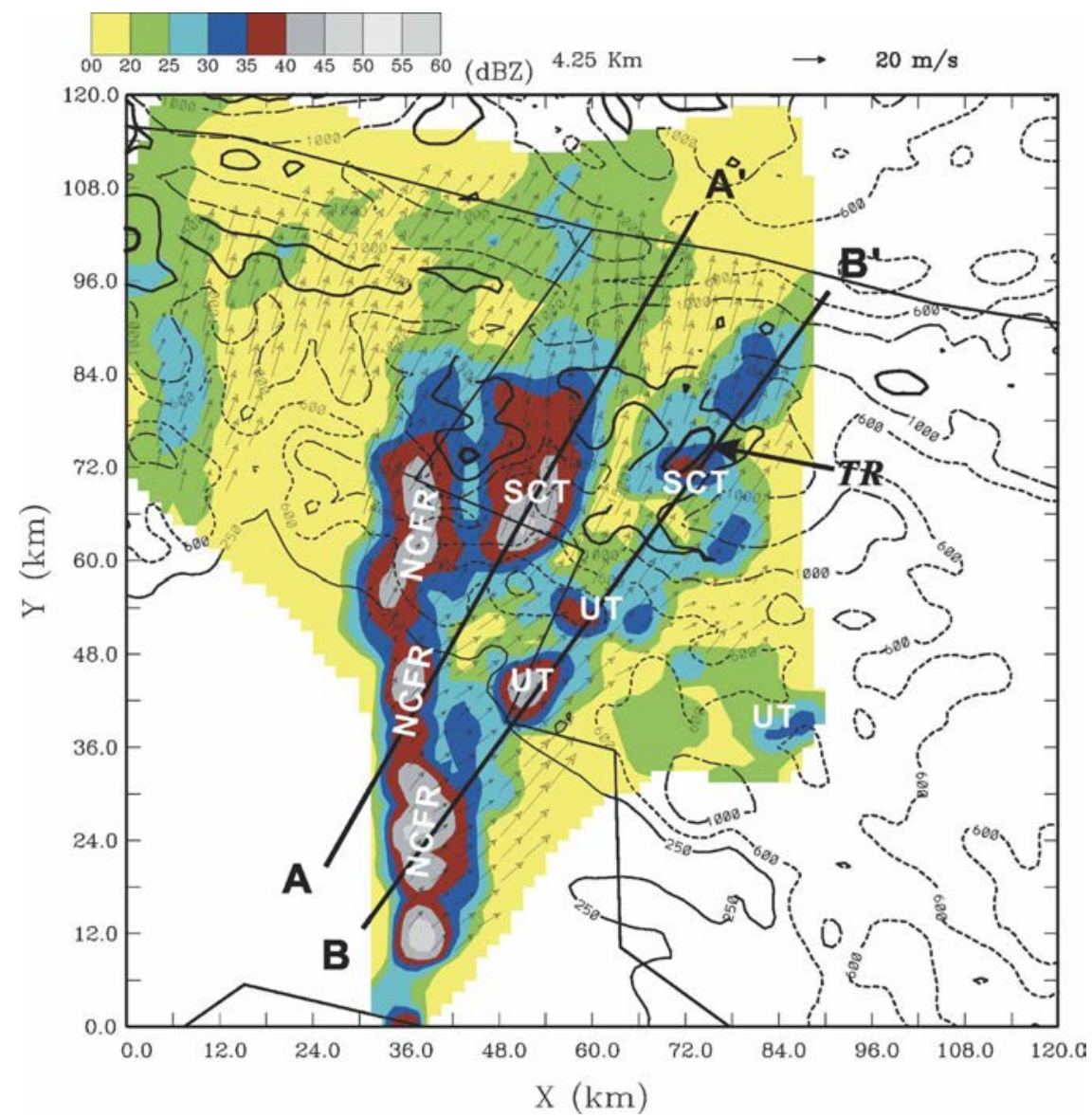

FIG. 10. Ground-relative wind vectors and radar reflectivity (dBZ, shading key at upper left) within domain D1 (location in Fig. 4) at 4.25-km MSL derived from the Electra airborne dual-Doppler analysis at 0720-0735 UTC 4 Oct 1999. Terrain height thresholds of 250, 600, 1000, 1500, and $2000 \mathrm{~m}$ MSL are indicated by solid, dashed, dash-dotted, thick solid, and dark thick solid contours, respectively. Arrow highlights the location of Mt. Triglav (TR). The locations of NCFR, SCT precipitation, and UT precipitation are indicated. Thick line segments $\mathrm{A}-\mathrm{A}^{\prime}$ and $\mathrm{B}-\mathrm{B}^{\prime}$ mark locations of vertical cross sections shown in Figs. 11 and 12.

the NCFR [often referred to as precipitation cores (PCs) and gap regions (GRs)] are similar to those of previously observed NCFRs (Hobbs and Biswas 1979; James and Browning 1979; Hobbs and Persson 1982; Jorgensen et al. 2003).

Considerable precipitation was also observed ahead of the observed NCFR over the southern slopes and near the mountain crest of the Julian Alps. The precipitation was much less organized (compared to the NCFR) and was marked by individual cells of enhanced radar reflectivities. As will be shown below, the occurrence of these precipitation cores appears related to different mechanisms. A vertical cross section $\left(\mathrm{A}-\mathrm{A}^{\prime}\right.$ in Fig. 10) running through a relatively large core of enhanced precipitation near $X=50 \mathrm{~km}, Y=66 \mathrm{~km}$ (i.e., immediately east of the northern end of the observed NCFR) and the observed NCFR, clearly shows the presence of the northerly continental flow from the north of the Julian Alps along the section (Fig. 11). The cold northerlies over the northern slopes of the Julian Alps appeared to be deep enough ( $\sim 3 \mathrm{~km}$ MSL) to pass over the mountain ridge and create a shallow downslope flow just overlying the southern slopes of the Julian Alps. The precipitation core was just located near the boundary between the northerly downslope flow and the southerly flow, where an enhanced lowlevel convergence was observed. The strongest reflectivity $(>45 \mathrm{dBZ})$ found within the precipitation core was elevated, just beneath the major updraft centers.

The low-level warm and moist southerly inflow entered the system from the southwest, and began to be lifted immediately ahead of the southern extent of the northerly downslope flow. Upward motions (with maximum vertical velocities of $\sim 4 \mathrm{~m} \mathrm{~s}^{-1}$ ) prevailed through- 

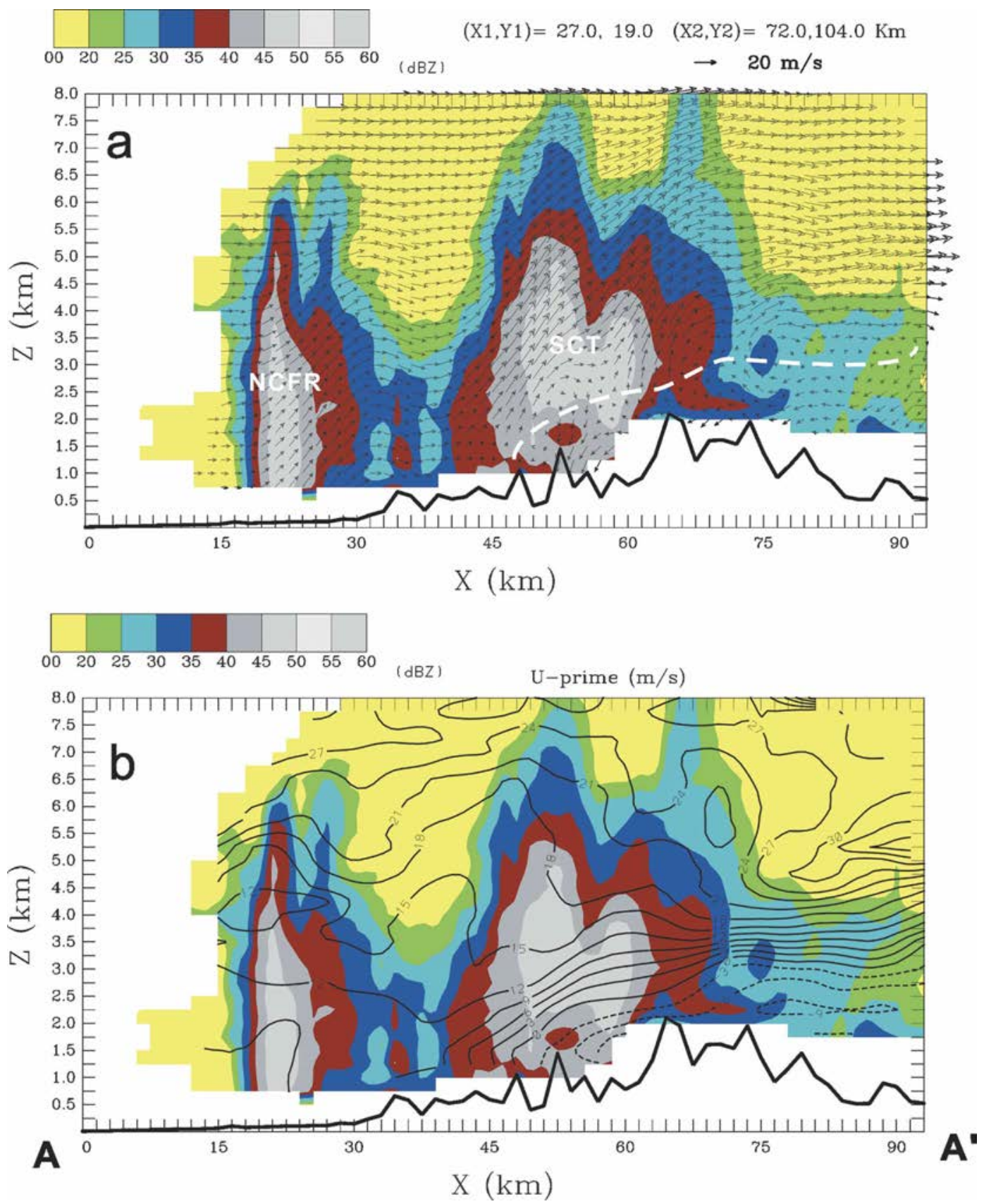

FIG. 11. Vertical cross section of dual-Doppler-derived ground-relative winds along A-A' in Fig. 10. (a) Wind vectors along the section. (b) The component of horizontal velocity parallel to the section with a contour interval of $3 \mathrm{~m} \mathrm{~s}^{-1}$. The shading in (a) and (b) indicates the field of radar reflectivity. Heavy solid line in the lower portion of (a) and (b) indicates topography along the section. Thick dashed line in (a) marks the $0 \mathrm{~m} \mathrm{~s}^{-1}$ along-section velocity, representing the vertical extent of the northerly flow. The locations of NCFR and SCT precipitation are also indicated in (a).

out the storm layer except for a shallow northerly downslope flow with relatively weak negative vertical velocity present in the lowest $1.5 \mathrm{~km}$ above the surface of the southern slopes. The strongest downward motion (with vertical velocities of $\sim 2 \mathrm{~m} \mathrm{~s}^{-1}$ ) associated with the downslope flow was found at $X=\sim 56 \mathrm{~km}$ imme- diately downstream of the most steep local slopes and was, however, coincident with the regions of heaviest precipitation near the ground and as such, it would be also probably intensified by liquid water loading. Given a rather moist condition in the lower troposphere for both the northerly continental flow and upstream flow 
(Figs. 7 and 9), the contribution of evaporative cooling to the intensification of the downward motions would be likely minor, compared to water loading. Both this prefrontal precipitation and the observed NCFR were characterized by a significant vertical extent of radar reflectivities, with the $40-\mathrm{dB} Z$ contour extending from the ground to a height of at least $\sim 5.5 \mathrm{~km}$. Such a convective nature is basically consistent with the deep layer of strong convective instability characterizing the prefrontal environment as shown in Fig. 8. This kind of precipitation, which formed over the mountain slopes through the convergence between the northerly flow originating to the northern slopes of the Julian Alps and the prefrontal southerly flow, will be referred to as slope convergence triggering (SCT) in the following descriptions.

The second vertical cross section (B-B' in Fig. 10) was selected to pass through those precipitation cells observed over the slopes of the highest terrain (Mt. Triglav) along the Julian Alps. Note that for this synthesis period, the flight track was primarily over the southern slopes and upstream of the Julian Alps so that some of the radar data at lower altitudes were missing over the northern side of Mt. Triglav due to the terrain blocking of the radar beam. To illustrate more complete airflow and precipitation structures on both the northern and southern sides of the mountains, synthesized fields derived from the dual-Doppler analysis period at 0746-0758 UTC, in which the aircraft flew over Mt. Triglav and was able to collect more available measurements on its northern side, are also incorporated into the vertical section (Fig. 12). In contrast to the foregoing vertical cross section shown in Fig. 11, the low-level northerly continental flow was confined to the northern slopes along the section and no evidence of this flow was observed over the southern slope of Mt. Triglav. The SCT precipitation collocated with the enhanced convergence between the northerly continental flow and the prefrontal southerly flow was also evident near the crest $(X=72 \mathrm{~km})$, although its associated maximum radar reflectivities (generally less than 40 $\mathrm{dBZ}$ ) were much weaker than that of the SCT precipitation located at the lower slopes shown in Fig. 11.

In Fig. 12, two other precipitation cells (between $X=$ $33 \mathrm{~km}$ and $X=60 \mathrm{~km}$ ) exhibiting an obvious convective nature were observed over the southern slopes of the Julian Alps. Particularly, low-level winds in regions of these precipitation cells were predominately upslope. The orographic lifting produced as the prefrontal south-southwesterlies encountered the southern slopes of the Julian Alps is suggested to be an important lowlevel forcing in triggering the moist deep convection. This kind of precipitation will be thus referred to as upslope triggering (UT) in the following descriptions. Doppler observations from different time periods (not shown) indicate that individual convective elements embedded within the UT precipitation were relatively short lived (less than one hour), with a trend to shift its location slightly northeastward (i.e., downstream of the prevailing southwesterly flow) with time.

\section{2) BASIC STRUCTURE OF THE 0834-0853 UTC ANALYSIS}

Results from subsequent analysis periods of dualDoppler synthesis provide further aspects of mountainous airflow and precipitation and their possible relation to the topographic effects. Figure 13 shows the 2-km horizontal structure of winds and precipitation derived from the dual-Doppler synthesis period at 0834-0848 and 0841-0853 UTC, corresponding to the analysis domain D2 and D3 (cf. Fig. 4), respectively. To demonstrate a more complete view of the airflow and precipitation patterns over the study region, results from the two analysis domains have been combined together in Fig. 13. During this time the NCFR, marked by a narrow intense reflectivity (highlighted by thick arrows in Fig. 13), just crossed over the border of Italy and Slovenia. The regions over the northern slopes of the Julian Alps were entirely occupied by the low-level northerly flow originating in the north of the eastern Alps. The northerly continental flow appeared to be able to pass over the lower mountain ridges between Mt. Triglav and Mt. Grintovec to reach the southern slopes of the Julian Alps. A relatively large core of heavy precipitation (SCT in Fig. 13) coincided with the boundary between this northerly flow and the prefrontal southerly flow. The vertical cross section $\left(\mathrm{C}-\mathrm{C}^{\prime}\right.$ indicated in Fig. 13) shows that the low-level southerly flow entered the precipitation core from the south, and began to be lifted near the southern leading edge of the cold northerly flow (Fig. 14). Maximum reflectivities and vertical velocities found within the core are generally comparable to those seen in Fig. 11.

It is important to note that there was also a clear indication of the northerly continental flow over the northern slopes of Julian Alps being deflected by the local highest terrain (i.e., Mt. Grintovec; Fig. 13). A weaker northeasterly flow $\left(\sim 3-5 \mathrm{~m} \mathrm{~s}^{-1}\right)$ seen south of Mt. Grintovec did not come directly from the northern slopes of the Julian Alps and appears to come around the eastern end of the Julian Alps. As revealed by a sounding at Ljubljana located $\sim 35 \mathrm{~km}$ south of Mt. Grintovec (asterisk in Fig. 13), the layer of the northeasterly flow extended from the ground to a height of $\sim 2 \mathrm{~km}$ and was characterized by stronger stratification and much colder temperatures (Fig. 15), compared to 

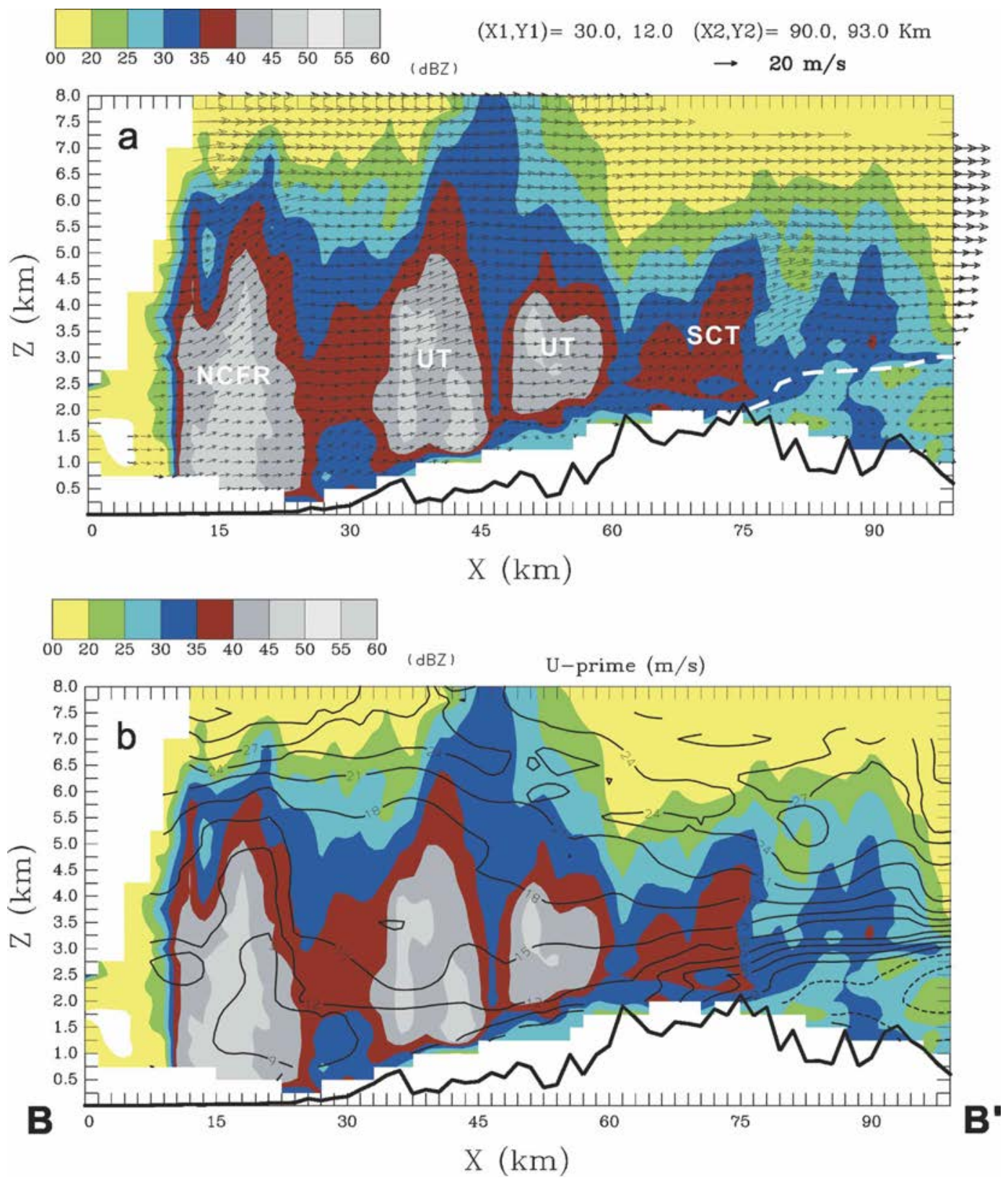

FIG. 12. Same as in Fig. 11 but along B-B' in Fig. 10. (a) The locations of NCFR, SCT precipitation, and UT precipitation are highlighted.

the prefrontal southerly flow (the P-3 dropsonde shown in Fig. 15). These observed features associated with the northerly continental flow are quite similar to those seen in the Graz sounding (cf. Figs. 8 and 9) located northeast of the Julian Alps (Fig. 4).

The vertical extent of the continental flow over this region was obviously lower than that observed over the northern slopes of the Julian Alps (cf. Fig. 11a). A deeper layer of the northerly continental flow generally found to the north of the Julian Alps is probably an indication of the accumulation of stable cold air due to orographic blocking as the continental flow encountered the steeper and higher northern slopes of the Julian Alps. Figure 13 also shows a cellular pattern of reflectivities observed ahead of the NCFR upstream of the windward slopes of the Julian Alps (with respect to the prefrontal south-southwesterly flow) that coincided with the confluent zone between the northeasterly flow and the prefrontal southerly flow. The vertical cross section (D-D' indicated in Fig. 13) indicates that the 


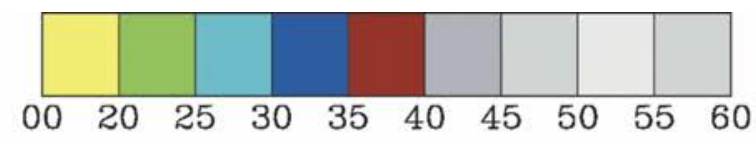

(dBZ)

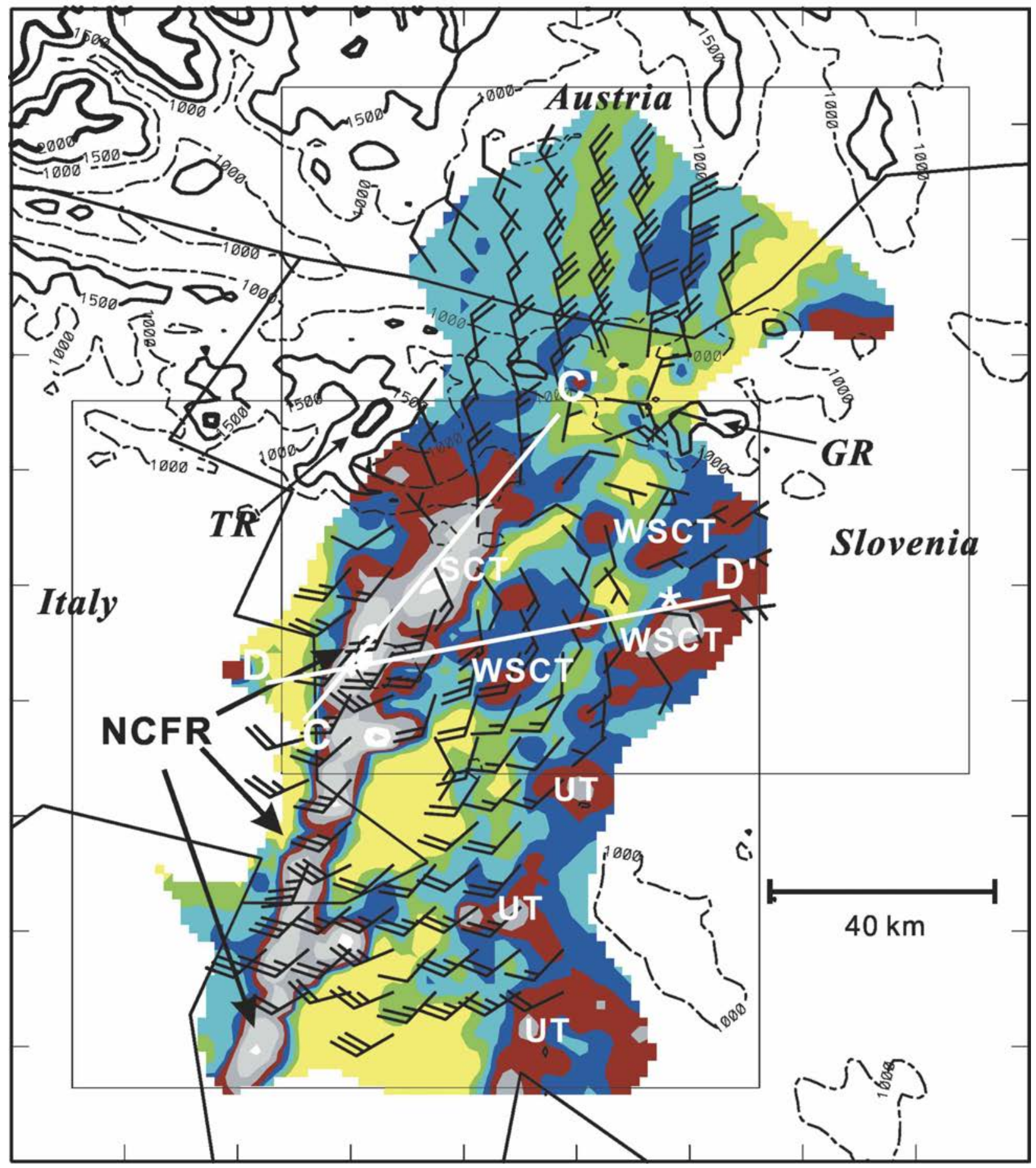

FIG. 13. The horizontal composite radar reflectivity ( $\mathrm{dBZ}$, shading key at top) and winds at 2-km height derived from two dualDoppler analysis domains [inset bottom (domain D2) and top (domain D3) boxes], corresponding to the P-3 synthesis times 0834-0848 and 0841-0853 UTC 4 Oct 1999, respectively. Full wind barbs correspond to $5 \mathrm{~m} \mathrm{~s}^{-1}$, half barbs to $2.5 \mathrm{~m} \mathrm{~s}^{-1}$. Terrain height thresholds of 1000, 1500, and $2000 \mathrm{~m}$ MSL are indicated by dash-dotted, thin, and thick contours, respectively. Locations of different forcing types of precipitation (NCFR, SCT, UT, and WSCT) are also highlighted. Thick line segments $\mathrm{C}^{-\mathrm{C}^{\prime}}$ and $\mathrm{D}-\mathrm{D}^{\prime}$ mark locations of vertical cross sections shown in Figs. 14 and 16. The asterisk marks the location of Ljubljana sounding to be shown in Fig. 15. Local mountain peaks, Mt. Triglav (TR) and Grintovec (GR), are also indicated. 

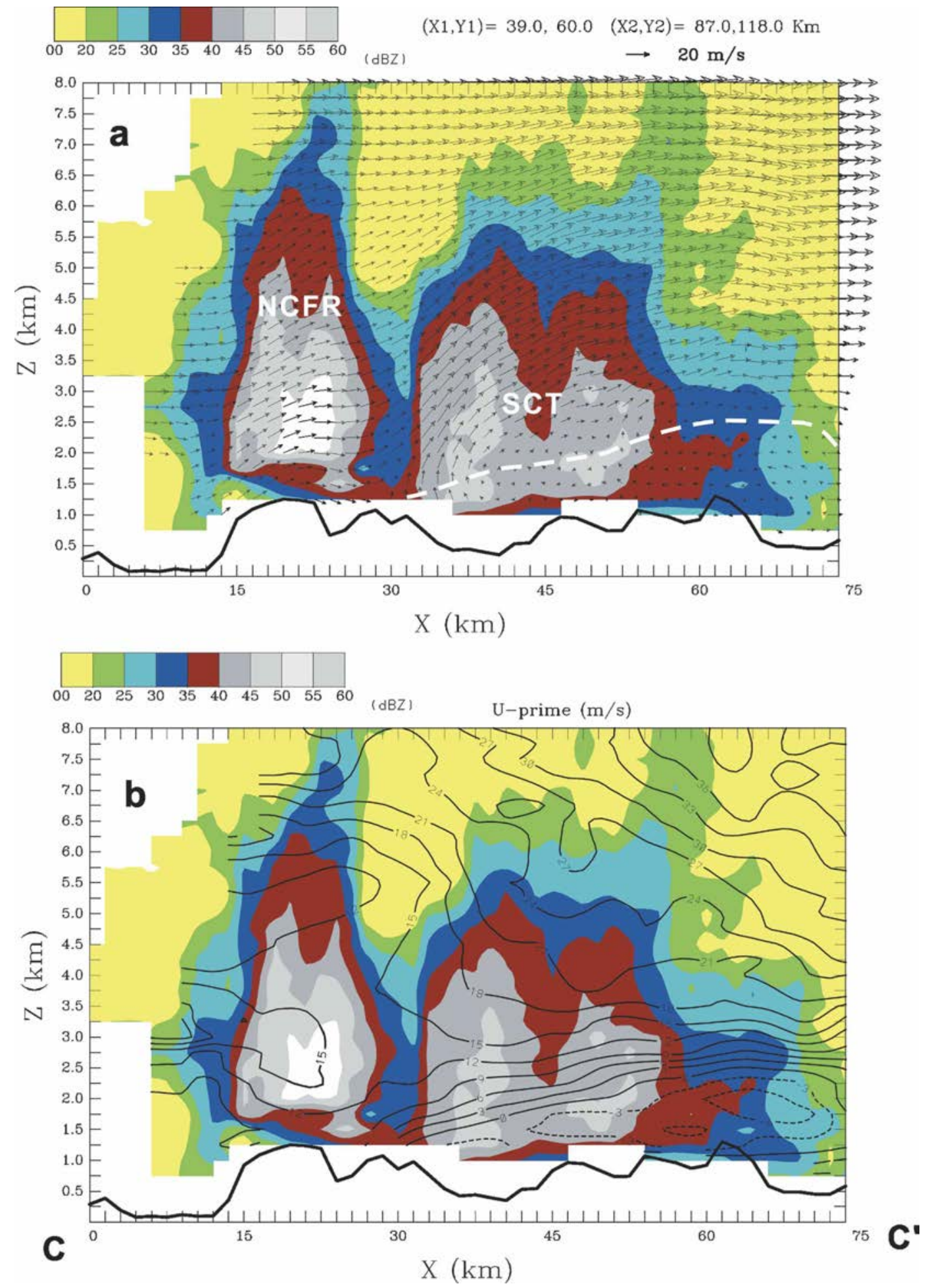

FIG. 14. Same as in Fig. 11 but along $\mathrm{C}-\mathrm{C}^{\prime}$ in Fig. 13. (a) The locations of NCFR and SCT precipitation are also highlighted. 


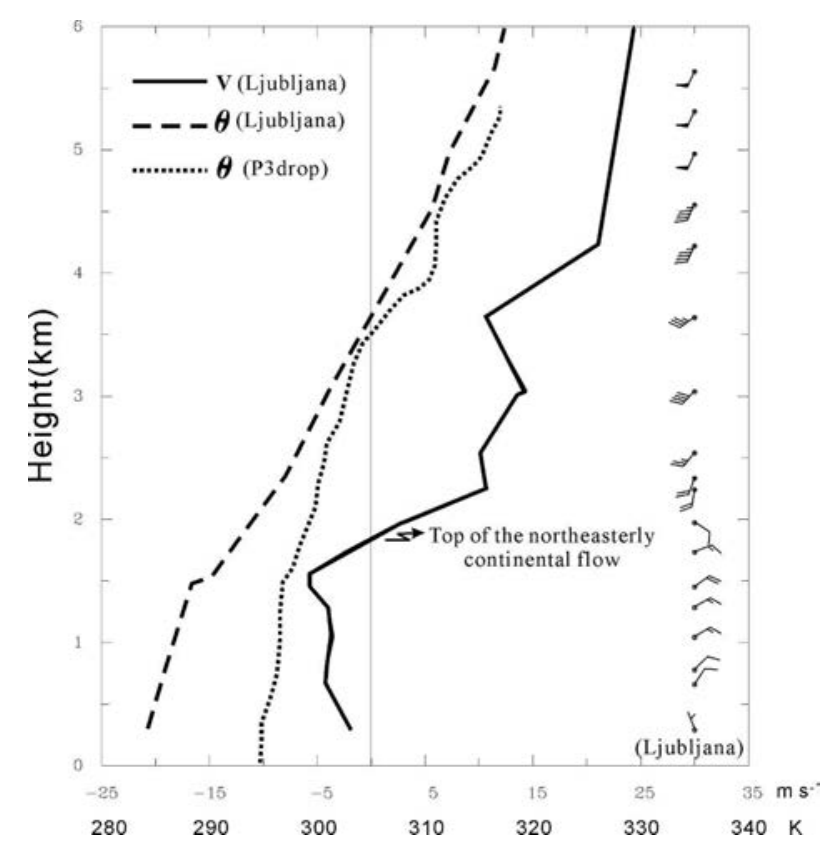

FIG. 15. Vertical profiles of potential temperature (dashed line), the northerly wind component (solid line), and wind (full and half wind barbs represent 5 and $2.5 \mathrm{~m} \mathrm{~s}^{-1}$, respectively) measured from the Ljubljana sounding (location indicated in Figs. 4 and 13) at 1200 UTC 4 Oct 1999. For comparison, the vertical profile of potential temperature from the P-3 dropsonde (dotted line) is indicated.

precipitation cells were distributed over a wider area extending from the southwestern edge of the cold northeasterly flow to a more northeastern region above it (Fig. 16). This feature suggests the importance of both the near-ground and more elevated lifting associated with the northeastward-sloping surface of the lowlevel cold northeasterly flow for triggering moist convection. Nevertheless, in contrast to the strong and predominately convective nature of the SCT precipitation, reflectivities (generally less than $40 \mathrm{dBZ}$ ) and vertical velocities associated with these cells were much weaker and the vertical extent of high reflectivities (the $40-\mathrm{dB} Z$ contour confined to heights below $\sim 3-4 \mathrm{~km}$ ) was also largely limited. These precipitation cells are thus referred to as weak slope convergence triggering (WSCT).

The reason for the weaker convective signature of the WSCT would be most likely related to the nature of the low-level forcing as well as the modification of the inflow by topography. As shown in Figs. 11 and 14, in distinct contrast to a more steep and deep sloping surface of the northerly flow associated with the SCT precipitation, the sloping surface of the cold northeasterly flow was inherently shallow and less steep (Fig. 16). When considering the sloping surface of the cold northerly flow as a material boundary, this feature implies a relatively weak low-level lifting, which may in turn influence the degree of how convection is triggered and formed. In addition, as shown in Fig. 13, the southwesterly and/or south-southwesterly flow prevailed ahead of the NCFR and tended to pass over the Dinaric Alps to reach the downstream region where the WSCT formed. The thermodynamical profile from a sounding at Ljubljana (released at 0000 UTC 4 October) indicates that the prefrontal southwesterly flow in the preconvection environment of the WSCT was characterized by relatively dry and warm conditions, particularly in the lowest $1.5 \mathrm{~km}$ (Fig. 17). Relative humidity was only about $64 \%$ at near-surface levels, which is much drier than that ( $\sim 83 \%)$ observed upstream of the Dinaric Alps (Fig. 7b). In addition, both the moisture content and the convective instability were also significantly reduced downstream of the Dinaric Alps. Above the mountain layer, the temperature and humidity profiles seen from this sounding were similar to those of the upstream sounding (cf. Fig. 7b). These observed features are consistent with the influences of the topographic effect; namely, the prefrontal southerly flow condenses over the southern slopes of the Dinaric Alps and descends on its lee side to stabilize the atmosphere.

During this analysis period, the UT precipitation (Fig. 13) was also found south of the WSCT precipitation over the windward slopes of the Dinaric Alps. In these regions, no obvious evidence of upstream blocking for the oncoming southwesterlies/south-southwesterlies was observed, consistent with a relatively large Froude number as described in section 3, and the upslope flow prevailed throughout the mountain layer. The UT precipitation was not characterized by a continuous, organized zone of heavy precipitation and, instead, similar to that shown in Fig. 10, was composed of individual cores of enhanced precipitation with a close connection to the triggering of moist convection by upslope forcing.

\section{3) Relation of precipitation to orographic FEATURES}

Airborne Doppler observations presented above indicate not only complicated features of airflow but also different forcing types of precipitation occurring in the vicinity of the Julian and Dinaric Alps. Particularly, a prominent spatial variation of the northerly continental flow over the mountainous region was observed to be a crucial factor influencing the distributions of enhanced precipitation. This aspect can be more clearly illustrated by a combination of the observed locations of the aforementioned SCT and WSCT precipitation and the southern extent of the northerly continental flow identified from the different synthesis periods (within $\sim 1.5$ 

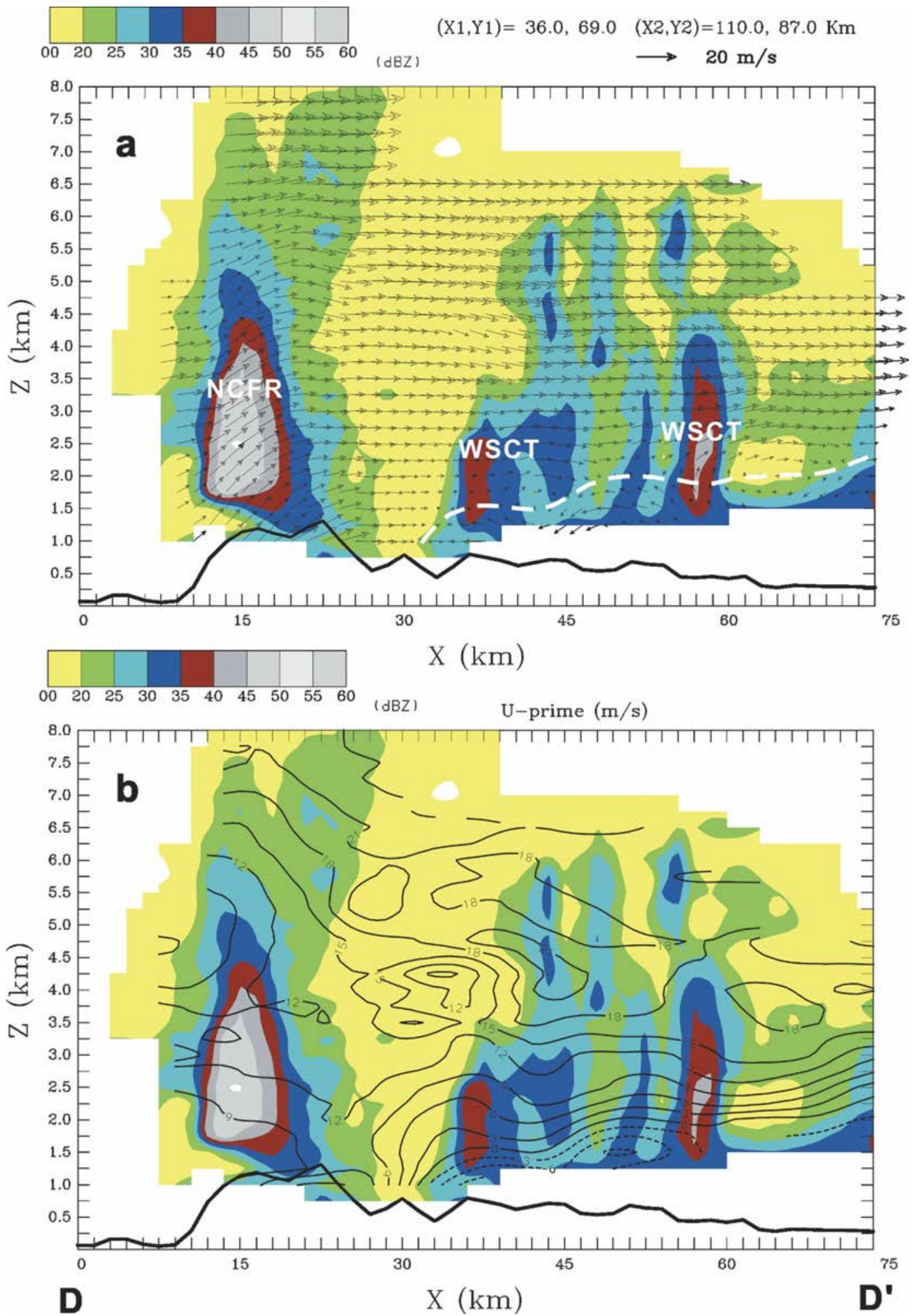

FIG. 16. Same as in Fig. 11 but along D-D' in Fig. 13. (a) The locations of WSCT precipitation and NCFR are highlighted. 


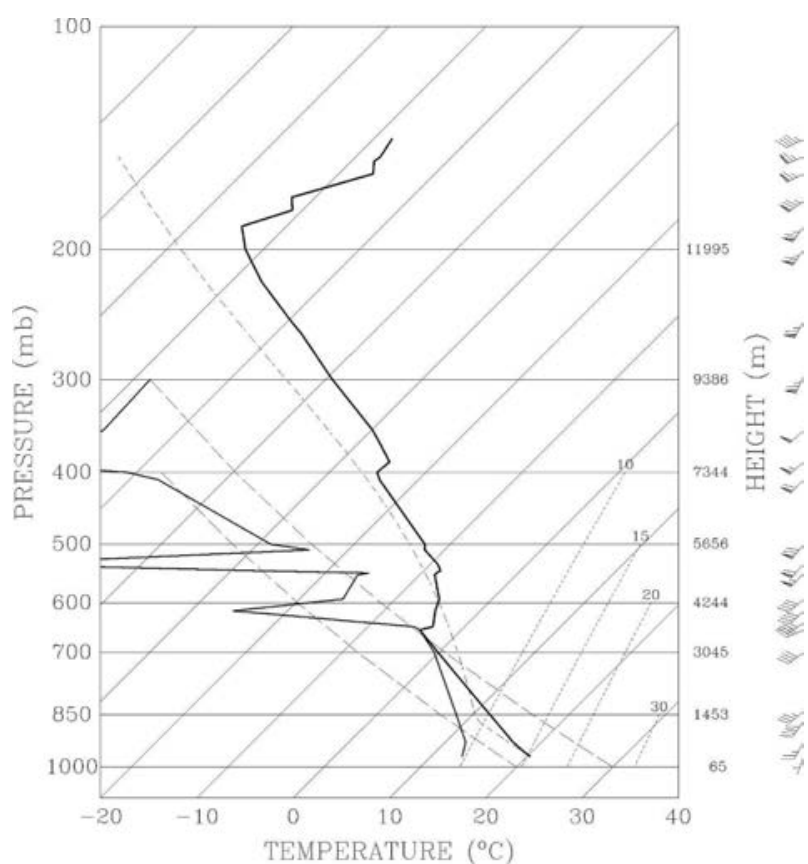

FIG. 17. Same as in Fig. 7 but showing the Ljubljana sounding taken at 0000 UTC 4 Oct 1999.

h from 0720 to 0853 UTC), as shown in Fig. 18. Southnorth profiles of mean terrain height at four selected locations are also indicated in Fig. 18. As described earlier and shown in Fig. 18, the SCT (WSCT) precipitation cores were located along the southern (south to western) edge of the northeasterly continental flow. It is apparent that the southern edge of the continental flow (indicated by heavy dashed line in Fig. 18) was not oriented exactly east-west as suggested by the synoptic analysis shown in Fig. 5, but varied significantly along the Julian Alps. Particularly, such a variation appears to result mainly from the influences of orographic blocking. As indicated in Fig. 18, the northerly continental flow was blocked by the local highest and steepest terrain such as the regions near Mt. Triglav and Mt. Grintovec and thus its southward extent was largely limited in these locations. In contrast, the continental flow tended to pass over less steep and lower terrain regions between mountain peaks to reach the more southern slopes of the Julian Alps. As such, although the orographic forcing would not be direct in triggering the SCT (WSCT) precipitation, their formative locations were in fact closely related to the orographic features.

Another interesting question regards whether the convective elements associated with the UT precipitation were formed at random locations over the windward slopes, or do they have some physical connection to the orographic features? Because the UT precipitation cells would probably move relative to the terrain surface during their lifetimes, the Doppler-observed location of the cells can be somewhat different from where they were initially formed. Uncertainties associated with the stage of evolution of each UT cell and the horizontal variation of thermodynamics also further complicate this issue. It is therefore not practical to explicitly evaluate the relationship between the locations of the UT cells and the terrain features in this study. As shown in Fig. 7, if the parcel is lifted from the surface, it would attain a temperature warmer than its environment within only a few hundred meters above the ground. This implies that deep convection can be triggered easily at lower mountain slopes. However, as shown in Figs. 10 and 13, the UT cells were located not only at lower mountain slopes but also over higher inland slopes. Some of the UT cells observed over higher slopes of the Dinaric Alps were found $\sim 60-70 \mathrm{~km}$ away from the upstream foothill where terrain begins to rise. This relatively large distance cannot be explained reasonably by the cell movement $\left(\sim 5 \mathrm{~m} \mathrm{~s}^{-1}\right.$ toward the north-northeast) if they are formed over the first mountain slope. Hence, it is very likely that the UT cells could also be triggered at higher inland steep slopes where orographic lifting is sufficient. This argument is consistent with the existence of the level of free convection (LFC) in the upstream sounding (cf, Fig. 7) for air parcels of both surface and higher-altitude origin.

\section{b. Dual-Doppler analysis during the latter portion of the flight}

As described in section 3, pronounced precipitation continued to occur over the study region during the later portion of the flight, as the surface cold front and its associated precipitation had just passed over the eastern end of the Julian Alps and reached the more southern segment of the Dinaric Alps (cf. Figs. 4 and 6). Regions in the vicinity of the Julian Alps and the northern portion of the Dinaric Alps were essentially postfrontal. During this flight period, the NOAA P-3 and the NCAR Electra aircraft executed three east-westoriented quad-Doppler flight patterns ${ }^{2}$ centered over the mountain peaks of the Julian Alps (cf. Fig. 6b). Because the flight track of the NOAA P-3 was over the southern slopes of the Julian Alps, it provides much better data coverage over the southern slopes of the Julian Alps than its northern slopes. In contrast, the flight track of the NCAR Electra was over the northern slopes; thus, major data coverage was confined to the

\footnotetext{
${ }^{2}$ Because there was a significant gap of radar data due to terrain blocking over the region suitable for the quad-Doppler synthesis, this study did not attempt to adopt this method to retrieve 3D kinematic fields.
} 

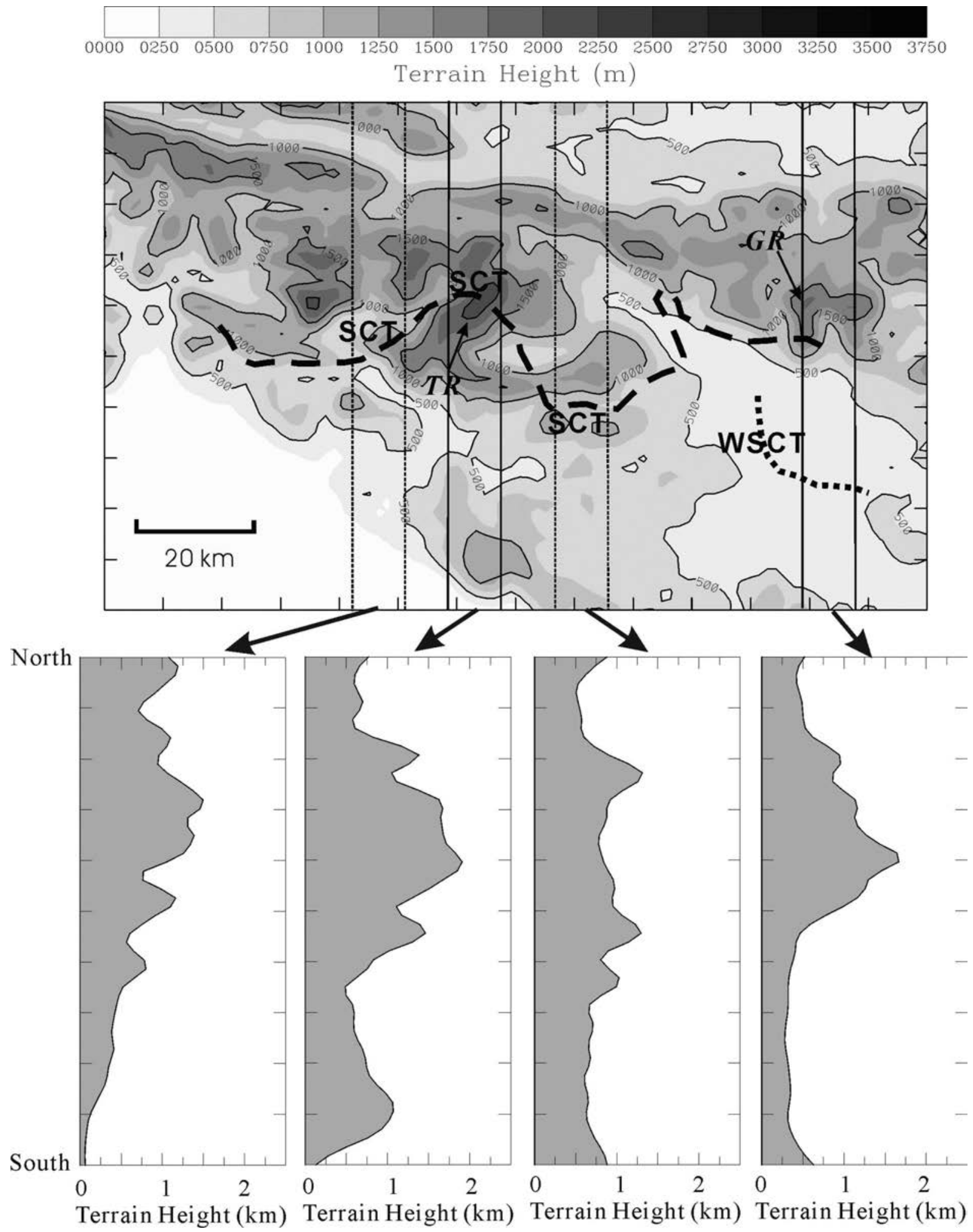

FIG. 18. Locations of SCT precipitation and WSCT precipitation observed from different dual-Doppler synthesis periods $(\sim 1.5 \mathrm{~h}$ from 0720 to 0853 UTC 4 Oct 1999). The zero northerly wind component contour at 2-km height is indicated by the heavy thick dashed line approximately locating the southern edge of the northeasterly continental flow directly from the northern slopes of the Julian Alps. Heavy dotted line indicates the southern/western boundary of the northeasterly continental flow originating from a region farther northeast of the Julian Alps. Terrain height (key at top) is shaded. Locations of Mt. Triglav (TR) and Grintovec (GR) are also indicated. South-north profiles of (bottom) terrain height along four select locations (top) marked by dotted/solid lines are also shown. 


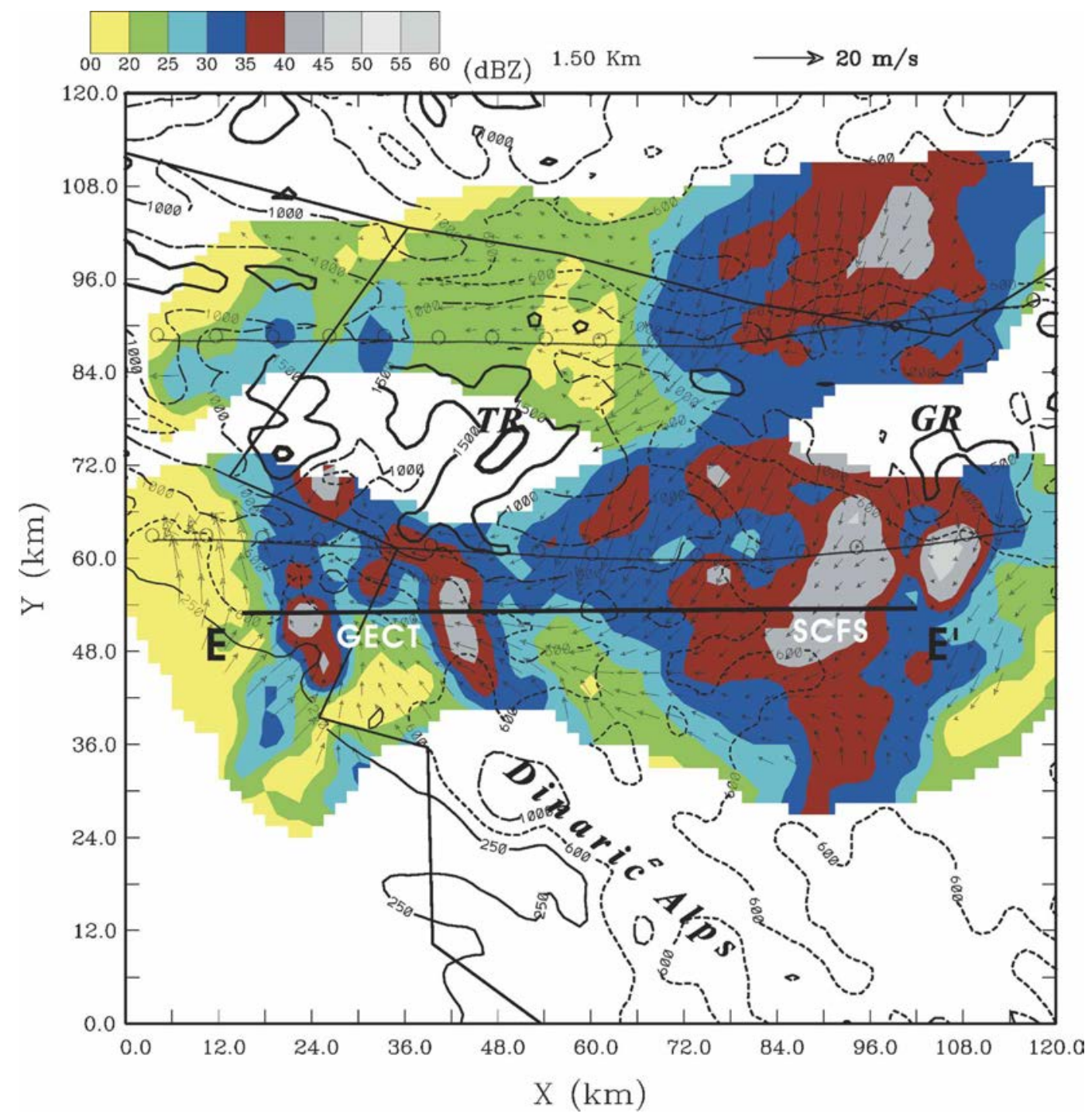

FIG. 19. Ground-relative wind vectors and radar reflectivity (dBZ, shading key at upper left) within the domain D4 (location indicated in Fig. 4) at 1.5-km MSL derived from the analysis period of 1024-1040 UTC (NOAA P-3) and 1023-1039 UTC (NCAR Electra) 4 Oct 1999. Terrain height thresholds of 250, 600, 1000, 1500, and $2000 \mathrm{~m}$ MSL are indicated by solid, dashed, dash-dotted, thick solid, and dark thick solid contours, respectively. The locations of GECT precipitation and SCFS precipitation are indicated. Thick line segment E-E' marks the location of the vertical cross section shown in Fig. 21. Two approximately horizontal lines with hollow circles (1-min interval) indicate the flight track of the NCAR Electra (the northern one) and the NOAA P-3 (the southern one) aircraft during the dual-Doppler synthesis period.

northern slopes. In pursuit of a more complete description of the airflow and precipitation patterns surrounding the Julian Alps, wind and reflectivity fields derived from the individual dual-Doppler synthesis period from two aircraft are combined together within the analysis domain (domain D4, Fig. 4). In those small areas where the individual synthesis fields overlay, a vector mean of the two wind measurements and a maximum of radar reflectivities are assumed to be representative of conditions at that grid point. Note that with the advantage of nearly the same observing period for the quadDoppler flight tracks between two aircraft, it is unlikely that this kind of combination would significantly distort the actual structure of mountainous wind and precipitation.

Figures 19 and 20 show the horizontal winds and radar reflectivity at 1.5 and $2.0 \mathrm{~km}$, respectively, derived from the first set of the quad-Doppler legs for the analysis period of 1024-1040 UTC (NOAA P-3) and 1023-1039 UTC (NCAR Electra). During this period, 


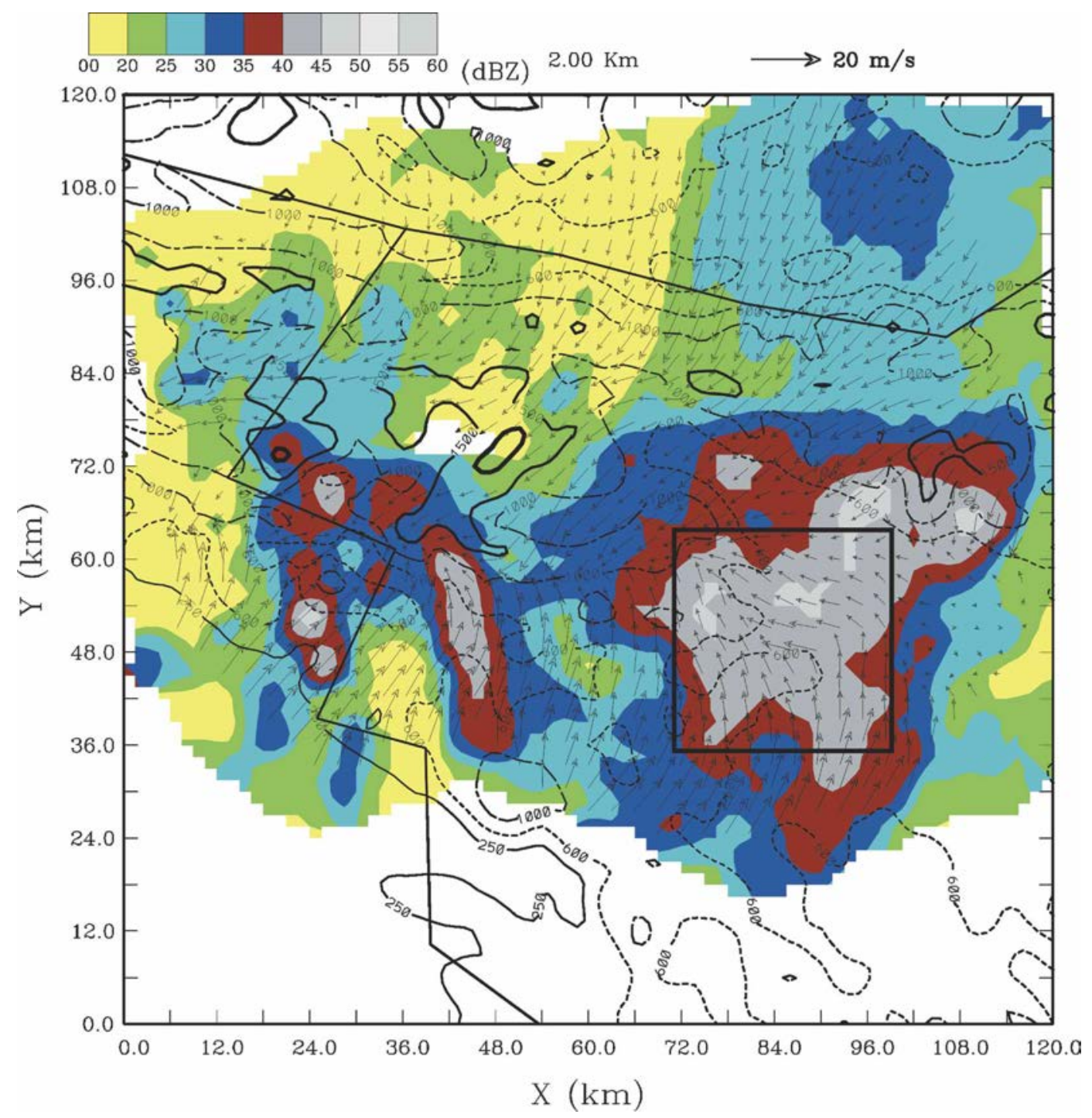

FIG. 20. Same as in Fig. 19 but at $2.0 \mathrm{~km}$ MSL. Inset box indicates the area $\left(27 \times 27 \mathrm{~km}^{2}\right)$ for calculating a mean profile of kinematic fields shown in Fig. 22.

enhanced precipitation was primarily confined to the regions south of the Julian Alps. In distinct contrast to a predominately convective nature of precipitation observed earlier in the flight, convective and stratiform precipitation appear to be both present over the study region. The convective precipitation [i.e., gap exit convergence triggering (GECT)] featured by several cores of enhanced reflectivity was found in the region immediately south/southwest of Mt. Triglav, where a prominent confluent zone between the postfrontal southwesterlies and the easterlies flowing out of the gap between Mt. Triglav and the northern end of the Dinaric Alps was observed. Presence of the easterly flow appears to result from the deflection of the northerly-tonortheasterly continental flow by the Dinaric Alps to become more parallel to the barrier. The easterly-tosoutheasterly flow found along the northern slopes of the Dinaric Alps existed only in the lowest $\sim 1.5 \mathrm{~km}$ (i.e., below the mountain height of the Dinaric Alps) but with the prevailing postfrontal southwesterly flow aloft. Similar to observations in the earlier flight, a prominent deflection, splitting, and deceleration of the continental flow by the local highest terrain (especially near Mt. Triglav) along the Julian Alps were also clearly evident at this time.

The vertical cross section (E-E' in Fig. 19) indicates that the postfrontal southwesterly flow was generally lifted upward over the sloping surface of the cold blocked easterly flow and that the precipitation of the GECT exhibited a convective nature but with much less 
vertical extent (the $40-\mathrm{dB} Z$ contour extending to a height of only $\sim 2.5-3 \mathrm{~km})$ and vertical velocities $(\sim 1$ $\mathrm{m} \mathrm{s}^{-1}$ ) than those of the SCT and UT precipitation documented in regions ahead of the surface front (Fig. 21). Given a drier and stronger postfrontal southwesterly wind in the mid- to high troposphere, as described in section 3, relatively shallow and weak features for the observed moist convection suggest that the entrainment process may play a significant role in reducing in-cloud buoyancy. Dual-Doppler synthesis results from the two sets of subsequent quad-Doppler flight track (not shown) indicate that the convective elements associated with the GECT were observed to weaken and dissipate at around $\sim 1113$ UTC.

A wider area of pronounced stratiform precipitation [i.e., slope convergence forced stratiform (SCFS)] with a relatively weak horizontal gradient of radar reflectivity was observed $\sim 25 \mathrm{~km}$ east of the GECT, immediately southwest of Mt. Grintovec over relatively flat terrain between the Julian and Dinaric Alps. Maximum reflectivities associated with the stratiform rain were comparable to those of the GECT and could reach above $40 \mathrm{dBZ}$. The vertical cross section shown in Fig. 21 indicates that a pronounced bright band characterizing the stratiform precipitation was found at the height of $\sim 2 \mathrm{~km}$ near the melting level. It is possible that the backward (eastward) transport of ice particles generated from the GECT would contribute to the formation of the SCFS. Nevertheless, dual-Doppler synthesis winds indicate that, except for the northerly continental flow present in the lowest $3 \mathrm{~km}$, the prevailing flow in the low to upper troposphere over the study region was predominately southwesterly, implying that the preferred location for the stratiform formation would be adjacent to the northeastern flank of the GECT instead of its eastern side as observed (cf. Fig. 20). In addition, as seen by a sequence of radar images from the airborne Doppler and Fossalon radar during this period (not shown), the precipitation for the GECT and SCFS was observed to occur nearly at the same time and no obvious evidence of developing time lag for these two types of precipitation was documented.

Hence, available observations did not suggest a close physical link between the SCFS precipitation and the GECT precipitation. Instead, as shown in Figs. 19 and 20 , over the stratiform region the northerly-tonortheasterly continental flow prevailed in the lowest $1.5 \mathrm{~km}$. In particular, this cold northerly flow encountered the postfrontal southwesterly-to-southerly flow to form a prominent confluent zone above $1.5 \mathrm{~km}$. The elevated lifting associated with the convergence between the postfrontal flow and the northerly continental flow appears to be crucial for the SCFS formation. A mean profile of kinematic fields (Fig. 22) taken from a $27 \times 27 \mathrm{~km}^{2}$ area encompassing the region of stratiform precipitation (box indicated in Fig. 20) show that relatively weak convergence associated with the blocking of the northerly continental flow by the Dinaric Alps was observed near ground level and the maximum convergence occurred near the height of $\sim 2 \mathrm{~km}$, which was corresponding to the observed confluent features seen in Fig. 20. As the continental flow became weaker at higher levels, the intensity of convergence between the two opposite flows decreased with height and the divergent flow dominated above $4 \mathrm{~km}$ (MSL). These orographically modified divergence patterns resulted in predominant upward (downward) motions above (below) $\sim 2 \mathrm{~km}$ (MSL). Inherent negative buoyancy of the cold continental flow and the latent cooling associated with the melting of ice particles would probably also favor the initiation of the downward motions at low levels. However, relatively large mean downward motions in the lowest levels are less representative owing to the reduced horizontal coverage of dual-Doppler data at these altitudes.

It is noteworthy that the presence of two distinct precipitation types (convective versus stratiform) for the GECT and SCFS over the study region could be understood as a consequence of their lifted air parcel and oncoming inflow having different origins. As shown in Fig. 22, when considering air parcels of a higheraltitude origin (due to a more elevated lifting at heights above $\sim 2 \mathrm{~km} \mathrm{MSL}$ ) for the SCFS, they would follow a colder pseudoadiabat and have correspondingly much lower and even near-zero CAPE (cf. Figs. 7a and 8). Furthermore, because the SCFS was located adjacent to the northern slopes of the Dinaric Alps, the postfrontal southerly flow feeding the SCFS may have been largely stabilized by topography as it passed over the Dinaric Alps (cf. Fig. 20), resulting in the forced ascent (instead of release of convective instability) of the southerly inflow by the underlying cold northerly continental flow. As evident in Fig. 17, stabilization of the southerly flow by the leeside orographic effect was indeed pronounced. In contrast, the GECT was just located over relatively low terrain near the gap between the Julian Alps and the northern end of the Dinaric Alps, where the low-level postfrontal southerly flow would feed the GECT directly with little modification by the orography.

\section{Conclusions}

The detailed airflow and precipitation structure over the mountainous regions near the border of northeastern Italy and Slovenia as a cold frontal system moved eastward and encountered the eastern Alps on 4 Octo- 


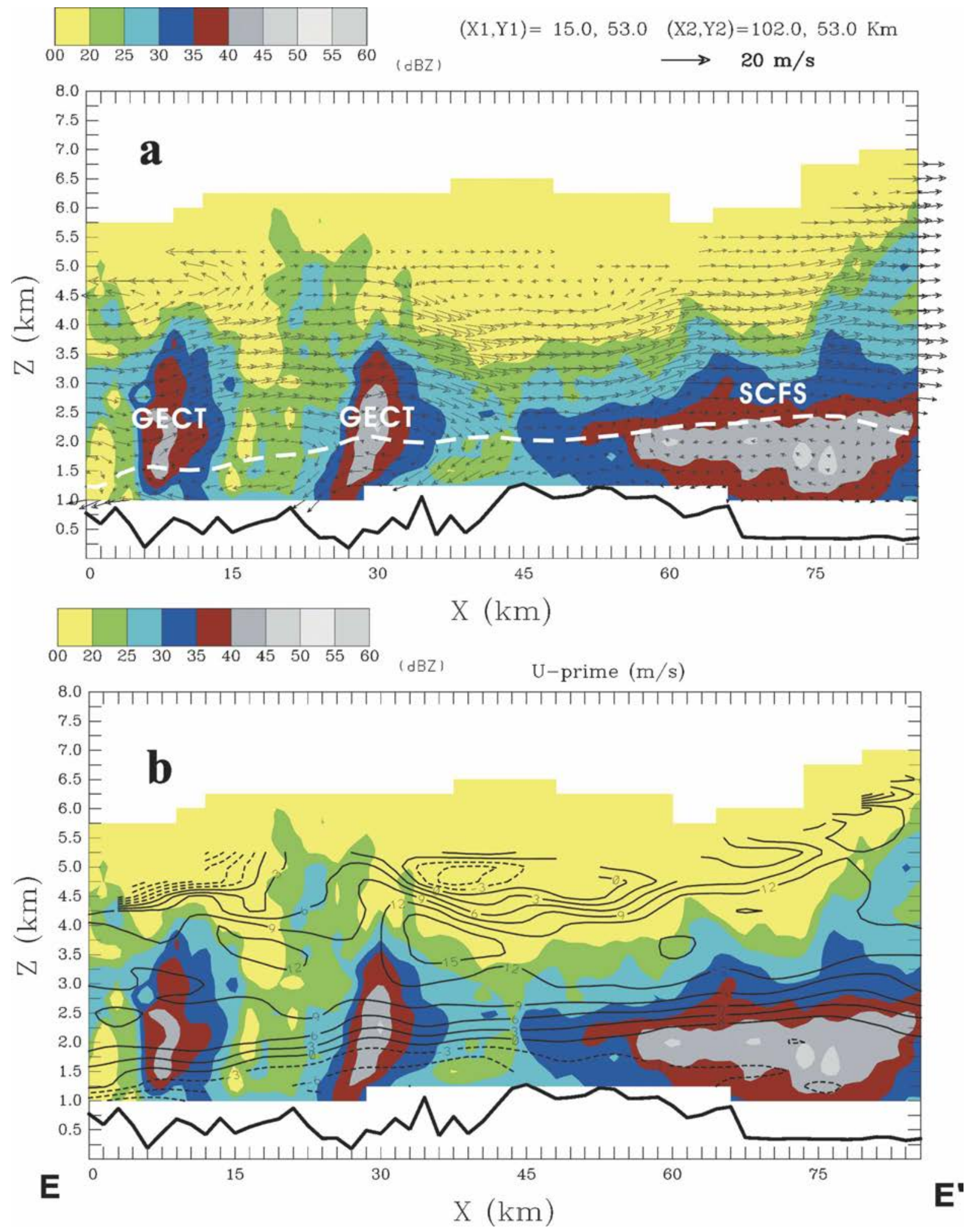

FIG. 21. Same as in Fig. 11 but along E-E' in Fig. 19. (a) Locations of GECT precipitation and SCFS precipitation are highlighted. 


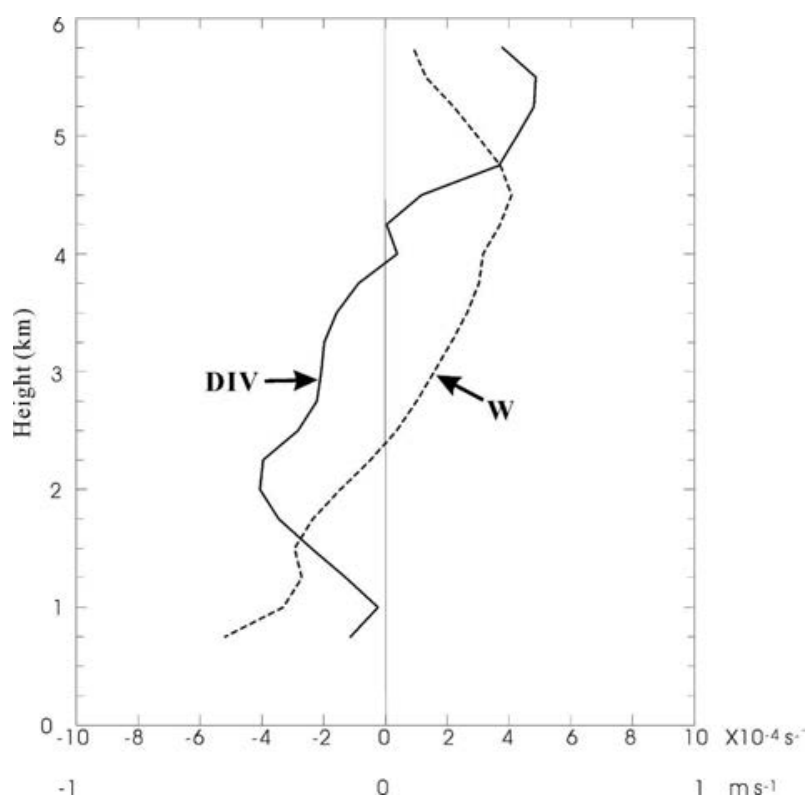

FIG. 22. Vertical profiles of area-averaged divergence (solid line) and vertical velocity (dashed line) over the box (location indicated in Fig. 20) encompassing the region of SCFS precipitation.

ber 1999 has been documented using airborne Doppler radar measurements from MAP IOP5. In this case, the environmental conditions are characterized by a deep layer of strong convective instability in the lower troposphere and by a cold, northeasterly continental flow coming down from the mountains (the so-called bora wind) along the southeastern Alps. Comprehensive analyses of airborne Doppler radar measurements have indicated five distinct forcing types of precipitation occurring over the study region, namely slope convergence triggering (SCT), upslope triggering (UT), weak slope convergence triggering (WSCT), gap exit convergence triggering (GECT), and slope convergence forced stratiform (SCFS). These important observational aspects are schematically summarized in Fig. 23.

During the early and midportion of the flight, as the front moved over the Julian Alps and the northern end of the Dinaric Alps, in addition to the observed NCFR coincident with the low-level frontal wind shift, the heavy precipitation occurred primarily in regions ahead of the surface front. SCT precipitation found over the southern slopes or the mountain crest of the Julian Alps was characterized by convective cores of enhanced reflectivities and the location of its associated precipitation cores coincided with the boundary between the northerly/northeasterly continental flow originating from the northern slopes of the Julian Alps and the prefrontal unstable south-southwesterly flow (Fig. 23a). The lifting that occurs as the prefrontal flow encounters the northerly downslope flow over the mountain slopes is a crucial low-level forcing for triggering of convection. The stable northerly continental flow was observed to be blocked by the local high and steep mountains and thus its southward extent was largely limited in these regions (cf. plan view I in Fig. 23). As a result, a more southern (northern) location of the precipitation cores was found downstream (with respect to the northerly continental flow) of relatively lower (higher) mountains along the Julian Alps.

The UT precipitation was observed over the windward (i.e., southern) slopes of the Dinaric Alps and over the southern slopes of the highest terrain of the Julian Alps where the northerly continental flow was confined to the northern slopes and thus the prefrontal southerly flow prevailed (Fig. 23b). Triggering of prefrontal potentially unstable air by a simple upslope lifting could explain the formation of this observed UT precipitation. Observations also suggest that the UT precipitation cells were initiated not only at lower mountain slopes but also over higher inland slopes, consistent with the existence of the level of free convection (LFC) in the upstream sounding for air parcels of both surface and higher-altitude origin.

WSCT precipitation was observed south of the highest mountain of the eastern portion of the Julian Alps over regions of relatively flat and low terrain (Fig. 23c). The convective forcing for this type of precipitation was also intimately related to the continental flow just like SCT was, but the low-level cold stable northeasterlies present underneath the precipitation cores did not originate from the northern slopes of the Julian Alps where the cold northerly continental flow was confined to the northern slopes of the high mountains due to orographic blocking. Instead its origin was from an area farther east of the study region. The southerly inflow feeding WSCT had been significantly stabilized due to the leeside effect as the prefrontal southerly flow passed over the Dinaric Alps. Also, the low-level continental cold air in this region was inherently shallow and its sloping surface was much less steep, compared with the northerly downslope flow associated with SCT precipitation. Therefore, the intensity of convection for WSCT in terms of its associated reflectivity and vertical velocity appeared to be much weaker than that of SCT.

As the front passed over the eastern end of the Julian Alps during the latter portion of the flight, the study region was essentially postfrontal and characterized by considerable precipitation. During this period, the lowlevel northeasterly continental flow originated either from the north or farther east of the Julian Alps and occupied most of the regions to the north of the Dinaric Alps. Deflection of the continental flow by the moun- 
(a)Slope Convergence Triggering(SCT)
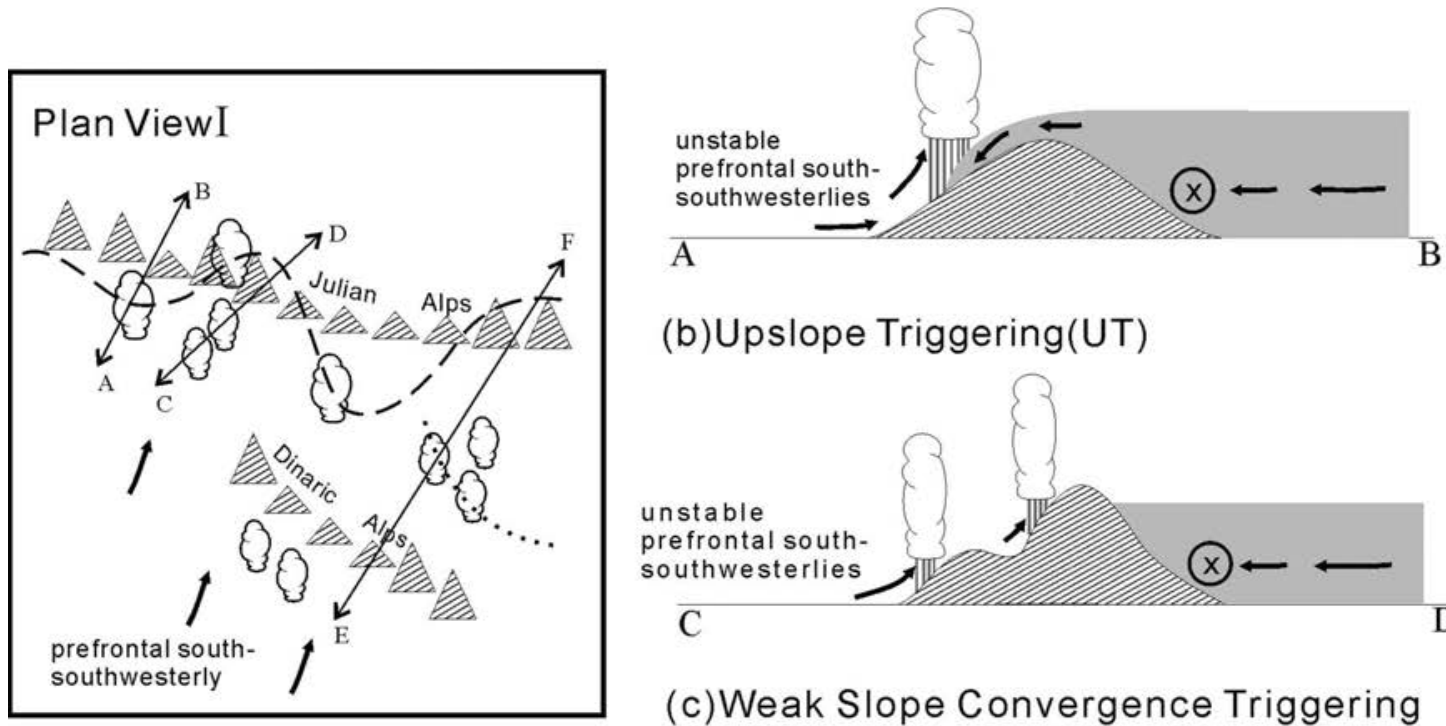

(b) Upslope Triggering(UT)

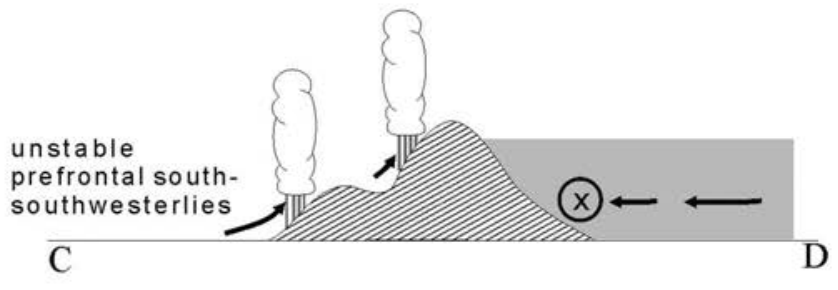

(c)Weak Slope Convergence Triggering (WSCT)

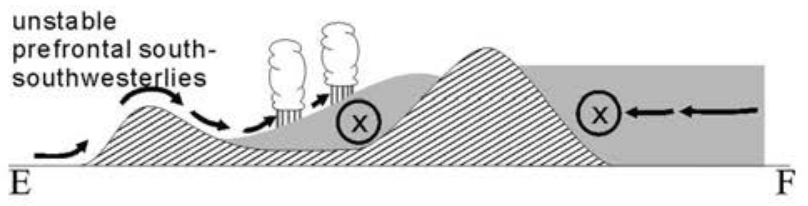

\section{(d)Gap Exit Convergence Triggering(GECT)}
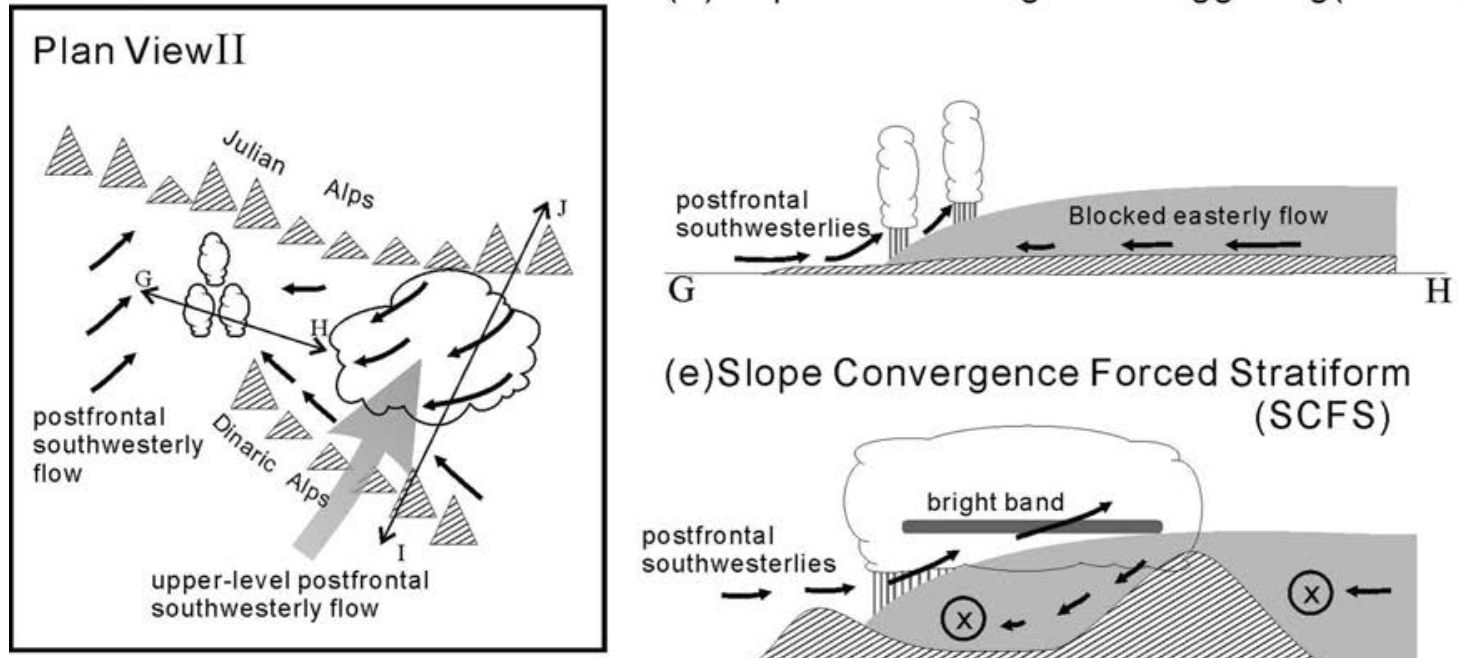

(e)Slope Convergence Forced Stratiform

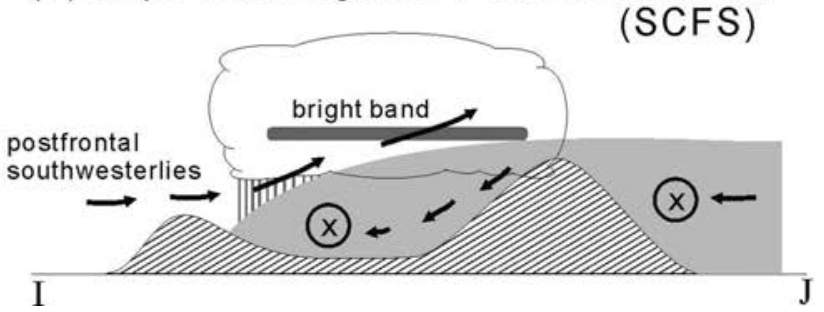

FIG. 23. Schematic diagram illustrating various precipitation mechanisms identified by airborne Doppler observations during MAP IOP5. The low-level horizontal airflow features and the locations of different forcing types of precipitation relative to the topography during the early to midportion (the latter) of the flight are indicated in plan view I (II). (right) The vertical cross sections (locations indicated in plan view) along each forcing type of precipitation (SCT, UT, WSCT, GECT, and SCFS) representative of their salient vertical airflow structures are indicated. In plan view I, the dashed line locates the southern edge of the northerly/northeasterly continental flow coming directly from the northern slopes of the Julian Alps, and the dotted line indicates the southern/western edge of the other branch of the northeasterly continental flow originating from a region farther northeast of the Julian Alps. (right) The shading and hatch represents the cold continental flow and terrain profile, respectively, and the hollow circle with a times sign indicates wind flowing into the plane of the section. 
tain range was also evident immediately north of the Dinaric Alps, resulting in the occurrence of easterly to southeasterly flow approximately parallel to the barrier (cf. plan view II in Fig. 23). GECT precipitation was just formed in the region of gap exit between the Julian Alps and the northern end of the Dinaric Alps, where the postfrontal southwesterly flow was lifted over the sloping surface of the cold blocked easterly flow (Fig. 23d). The precipitation cells associated with GECT exhibited a relatively shallow and weak convective nature, which is likely due to an enhanced entrainment effect in a drier postfrontal environment.

SCFS precipitation observed east of GECT was predominately stratiform and more widespread. The elevated lifting associated with the convergence between the postfrontal southwesterly flow and the cold northerly continental flow was important for the formation of this stratiform precipitation (Fig. 23e). A more elevated lifting (i.e., air parcels of a higher-altitude origin) for SCFS also implies a much lower convective instability than GECT. Moreover, in contrast to GECT with little modification of its postfrontal southerly inflow by upstream orography, the postfrontal southerly inflow feeding SCFS is expected to have stabilized as it passed over the Dinaric Alps. Different origins for the lifted air parcels and the oncoming inflow may explain two distinct precipitation types (convective versus stratiform), both present over the study region.

This study has revealed the rather complicated nature of orographic precipitation developing in a potentially unstable environment, as well as significant precipitation variation in terms of its location, intensity, and type. These characteristics appeared to be closely related to the environmental thermodynamics, orographic features, and the interactions between the southerly to southwesterly flow, the northerly continental flow, and the orography. Moreover, multiple precipitation mechanisms also appeared to occur simultaneously in the mountain vicinity. It is clear that without detailed Doppler radar observations over mountains, these important aspects of orographic precipitation cannot be revealed. However, one of the major difficulties in documenting the evolution of the different forcing types of precipitation with airborne Doppler radar result from a relatively large time interval $(\geq 30$ min) between two successive flight legs over a similar area. The inherently short-lived nature of the convective cells (less than $\sim 1 \mathrm{~h}$ ) embedded within the observed precipitation and the influences of terrain blockage on radar observations further make the documentation of rapidly evolving characteristics of individual convective cells impractical in this case. Future detailed measurements of thermodynamics, kinematics, and precipitation collected over mountains in different synoptic environments, as well as the verification of a highresolution numerical model, will be crucial to allow various aspects of orographic precipitation to be identified and to further improve our general understanding of physical processes active over complex terrain.

Acknowledgments. We thank the efforts of the NCAR Electra and NOAA P-3 flight crews for their dedication and support during MAP. Special thanks to B. Smull for his advice and assistance on the collection of airborne Doppler radar data during MAP IOP5 and to Dr. W.-C. Lee for his recommendation on the processing of airborne Doppler radar data during the MAP experiment. We thank Dr. J. Doyle and two anonymous reviewers for providing insightful comments that improved the manuscript. We also extend thanks to J.-L. Wu, A.-X. Ou, and Y.-H. Hung for their assistance in editing the airborne Doppler radar data, as well as to C. Gudmundson for editing the manuscript. Surface and sounding data analyzed in this study were provided by the MAP Data Centre. Participation of the first author in the MAP Special Observing Period in Innsbruck and this study were supported by the National Science Council of the Republic of China under Grants NSC 88-2119-M002-002, NSC 94-2111-M-034-001, and NSC 95-2111-M-034-001.

\section{REFERENCES}

Asencio, N., J. Stein, M. Chong, and F. Gheusi, 2003: Analysis and simulation of local and regional conditions for the rainfall over the Lago Maggiore target area during MAP IOP $2 b$. Quart. J. Roy. Meteor. Soc., 129, 565-586.

Banta, R. M., and Coauthors, 1990: Atmospheric Processes over Complex Terrain. Meteor. Monogr., No. 45, Amer. Meteor. Soc., 323 pp.

Bond, N. A., and Coauthors, 1997: The Coastal Observation and Simulation with Topography (COAST) experiment. Bull. Amer. Meteor. Soc., 78, 1941-1955.

Bougeault, P., and Coauthors, 2001: The MAP special observing period. Bull. Amer. Meteor. Soc., 82, 433-462.

Bousquet, O., and B. F. Smull, 2003: Airflow and precipitation fields within deep Alpine valleys observed by airborne Doppler radar. J. Appl. Meteor., 42, 1497-1513.

Browning, K. A., F. F. Hill, and C. W. Pardoe, 1974: Structure and mechanism of precipitation and the effect of orography in a wintertime warm sector. Quart. J. Roy. Meteor. Soc., 100, 309-330.

Buzzi, A., and L. Foschini, 2000: Mesoscale meteorological features associated with heavy precipitation in the southern Alpine region. Meteor. Atmos. Phys., 72, 131-146.

Caracena, F., R. A. Maddox, L. R. Hoxit, and C. F. Chappell, 1979: Mesoanalysis of the Big Thompson Storm. Mon. Wea. Rev., 107, 1-17.

Chen, G. T.-J., H.-C. Chou, J.-S. Yang, and S.-Y. Chen, 1999: Case study of a spring squall line accompanied by hailstorm occurrence in northern Taiwan (in Chinese with English abstract). Atmos. Sci., 27, 257-271. 
Chen, S.-H., and Y.-L. Lin, 2005: Orographic effects on a conditionally unstable flow over an idealized three-dimensional mesoscale mountain. Meteor. Atmos. Phys., 88, 1-21.

Chiao, S., Y.-L. Lin, and M. L. Kaplan, 2004: Numerical study of the orographic forcing of heavy precipitation during MAP IOP-2B. Mon. Wea. Rev., 132, 2184-2203.

Colle, B. A., and C. F. Mass, 1996: An observational and modeling study of the interaction of low-level southwesterly flow with the Olympic Mountains during COAST IOP 4. Mon. Wea. Rev., 124, 2152-2175.

Cox, J. A. W., W. J. Steenburgh, J. C. Shafer, D. E. Kingsmill, H. Cai, B. A. Colle, O. Bousquet, and B. F. Smull, 2005: The kinematic structure of a Wasatch Mountain winter storm during IPEX IOP 3. Mon. Wea. Rev., 133, 521-542.

Frei, C., and C. Schär, 1998: A precipitation climatology of the Alps from the high-resolution rain-gauge observations. Int. J. Climatol., 18, 873-900.

Galewsky, J., and A. Sobel, 2005: Moist dynamics and orographic precipitation in northern and central California during the New Year's Flood of 1997. Mon. Wea. Rev., 133, 1594-1612.

Garvert, M. F., C. P. Woods, B. A. Colle, C. F. Mass, P. V. Hobbs, M. T. Stoelinga, and J. B. Wolfe, 2005: The 13-14 December 2001 IMPROVE-2 event. Part II: Comparisons of MM5 model simulations of clouds and precipitation with observations. J. Atmos. Sci., 62, 3520-3534.

Georgis, J.-F., F. Roux, and P. H. Hildebrand, 2000: Observation of precipitating systems over complex orography with meteorological Doppler radars: A feasibility study. Meteor. Atmos. Phys., 72, 185-202.

,,-- M. Chong, and S. Pradier, 2003: Triple-Doppler radar analysis of the heavy rain event observed in the Lago Maggiore region during MAP IOP 2b. Quart. J. Roy. Meteor. Soc., 129, 495-522.

Grossman, R. L., and D. R. Durran, 1984: Interaction of low-level flow with the western Ghat Mountains and offshore convection in the summer monsoon. Mon. Wea. Rev., 112, 652-672.

Hobbs, P. V., and K. R. Biswas, 1979: The cellular structure of narrow cold-frontal rainbands. Quart. J. Roy. Meteor. Soc., 105, 723-727.

— , and P. O. G. Persson, 1982: The mesoscale and microscale structure of clouds and precipitation in midlatitude cyclones. $\mathrm{V}$ : The substructure of narrow cold frontal rainbands. $J$. Atmos. Sci., 39, 280-295.

Houze, R. A., Jr., 1993: Cloud Dynamics. Academic Press, 573 pp.

— , and S. Medina, 2005: Turbulence as a mechanism for orographic precipitation enhancement. J. Atmos. Sci., 62, 35993623.

James, P. K., and K. A. Browning, 1979: Mesoscale structure of line convection at surface cold fronts. Quart. J. Roy. Meteor. Soc., 105, 371-382.

Jorgensen, D. P., T. Matejka, and J. D. DuGranrut, 1994: Multibeam techniques for deriving wind fields from airborne Doppler radars. Meteor. Atmos. Phys., 59, 83-104.

—, Z. Pu, P. O. G. Persson, and W.-K. Tao, 2003: Variations associated with cores and gaps of a Pacific narrow cold frontal rainband. Mon. Wea. Rev., 131, 2705-2729.

Jou, B. J.-D., 1994: Mountain-originated mesoscale precipitation system in northern Taiwan: A case study of 21 June 1991. Terr. Atmos. Oceanic Sci., 5, 169-197.

Kirshbaum, D. J., and D. R. Durran, 2004: Factors governing cellular convection in orographic precipitation. J. Atmos. Sci., 61, 682-698.

Kljun, N., M. Sprenger, and C. Schär, 2001: Frontal modification and lee cyclogenesis in the Alps: A case study using the ALPEX reanalysis data set. Meteor. Atmos. Phys., 78, 89106.

Lazić, L., and I. Tošić, 1998: A real data simulation of the Adriatic bora and the impact of mountain height on bora trajectories. Meteor. Atmos. Phys., 66, 143-155.

Lin, Y.-L., H. D. Reeves, S.-Y. Chen, and S. Chiao, 2005: Formation mechanisms for convection over the Ligurian Sea during MAP IOP-8. Mon. Wea. Rev., 133, 2227-2245.

Matejka, T., and D. L. Bartels, 1998: The accuracy of vertical air velocities from Doppler radar data. Mon. Wea. Rev., 126, 92-117.

Medina, S., and R. A. Houze Jr., 2003: Air motions and precipitation growth in Alpine storms. Quart. J. Roy. Meteor. Soc., 129, 345-371.

, B. F. Smull, R. A. Houze Jr., and M. Steiner, 2005: Crossbarrier flow during orographic precipitation events: Results from MAP and IMPROVE. J. Atmos. Sci., 62, 3580-3598.

Neiman, P. J., P. O. G. Persson, F. M. Ralph, D. P. Jorgensen, A. B. White, and D. E. Kingsmill, 2004: Modification of fronts and precipitation by coastal blocking during an intense landfalling winter storm in southern California: Observations during CALJET. Mon. Wea. Rev., 132, 242-273.

Parsons, D. B., and P. V. Hobbs, 1983: The mesoscale and microscale structure and organization of clouds and precipitation in midlatitude cyclones. IX: Some effects of orography on rainbands. J. Atmos. Sci., 40, 1930-1949.

Pradier, S., M. Chong, and F. Roux, 2002: Radar observations and numerical modeling of a precipitating line during MAP IOP 5. Mon. Wea. Rev., 130, 2533-2553.

$\longrightarrow,-$, and 2005: Characteristics of some frontal stratiform precipitation events south of the Alpine chain during MAP. Meteor. Atmos. Phys., 87, 197-218.

Ralph, F. M., and Coauthors, 1999: The California Land-Falling Jets Experiment (CALJET): Objectives and design of a coastal atmosphere-ocean observing system deployed during a strong El Niño. Preprints, Third Symp. on Integrated $\mathrm{Ob}$ serving Systems, Dallas, TX, Amer. Meteor. Soc., 78-81.

Richard, E., S. Cosma, P. Tabary, J. P. Pinty, and M. Hagen, 2003: High-resolution numerical simulation of the convective system observed in the Lago Maggiore area on 17 September 1999 (MAP IOP 2a). Quart. J. Roy. Meteor. Soc., 129, $543-$ 563.

Schultz, D. M., and Coauthors, 2002: Understanding Utah winter storms: The Intermountain Precipitation Experiment. Bull. Amer. Meteor. Soc., 83, 189-210.

Smith, R. B., 1979: The influence of mountains on the atmosphere. Advances in Geophysics, Vol. 21, Academic Press, 87-230.

_ 1982: A differential model of thermal advection. Mon. Wea. Rev., 110, 306-309.

, 1987: Aerial observations of the Yugoslavian Bora. J. Atmos. Sci., 44, 269-297.

Stoelinga, M. T., and Coauthors, 2003: Improvement of microphysical parameterization through observational verification experiments. Bull. Amer. Meteor. Soc., 84, 1807-1826.

Woods, C. P., M. T. Stoelinga, J. D. Locatelli, and P. V. Hobbs, 2005: Microphysical processes and synergistic interaction between frontal and orographic forcing of precipitation during the 13 December 2001 IMPROVE-2 event over the Oregon Cascades. J. Atmos. Sci., 62, 3493-3519.

Yu, C.-K., and B. F. Smull, 2000: Airborne Doppler observations of a landfalling cold front upstream of steep coastal orography. Mon. Wea. Rev., 128, 1577-1603. 